\title{
Role of the State-of-the-Art Three-dimensional Ultrasound in the Differentiation of Benign and Malignant Ovarian Masses
}

\author{
${ }^{1}$ Francisco Bonilla Jr, ${ }^{2}$ Francisco Raga, ${ }^{3}$ Oscar Caballero, ${ }^{4}$ Juan Carlos Castillo \\ ${ }^{5}$ Luiz Eduardo Machado, ${ }^{6}$ Fernando Bonilla-Musoles
}

\begin{abstract}
Modern three-dimensional (3D) ultrasound tools, HDlive and radiance system architecture or silhouette offer unique ways for assessing women with ovarian masses; providing realistic 3D reconstructions of the ovarian tumors, together with essential information to facilitate the differentiation between benignity and malignancy of ovarian masses.
\end{abstract}

Keywords: Ovarian cancer, Ovarian malignancy, Ovarian masses, Ovarian tumors, Power Doppler, Three-dimensional ultrasound.

How to cite this article: Bonilla F Jr, Raga F, Caballero O, Castillo JC, Machado LE, Bonilla-Musoles F. Role of the Stateof-the-Art Three-dimensional Ultrasound in the Differentiation of Benign and Malignant Ovarian Masses. Donald School J Ultrasound Obstet Gynecol 2015;9(4):446-461.

Source of support: Nil

Conflict of interest: None

\section{INTRODUCTION}

Due to its complex embryologic development involving the three embryonic layers, the ovary can be the location of a large list of primary tumors and cancers; only comparable in variety and malignancy to those occurring within the central nervous system.

Albeit its low incidence (only $5 \%$ of all types of cancer in women), ovarian cancer is a leading cause of mortality among gynecologic cancers; moreover, from 20 to $30 \%$ of all ovarian tumors irrespective of age at diagnosis are malignant.

Many factors contribute to the elevated mortality rate, including the incidence of malignancies of aggressive

1,2,3,5 Professor, ${ }^{4}$ Researcher, ${ }^{6}$ Professor and Chairman

${ }^{1-3,6}$ Department of Obstetrics and Gynecology, School of Medicine, University of Valencia, Spain

${ }^{4}$ Assisted Reproduction Unit, Instituto Bernabéu, Alicante, Spain

${ }^{5}$ Department of Obstetrics and Gynecology, Federal University of Salvador, Bahia, Brazil

Corresponding Author: Fernando Bonilla-Musoles, Professor and Chairman, Department of Obstetrics and Gynecology School of Medicine, University of Valencia, Navarro Reverter 11, 46004 Valencia, Spain, e-mail: profesorbonillamusoles@ hotmail.com histologic variety (embryonic tumors), the higher lifespan expectancy of women in modern societies which increases the chance of developing age-related diseases and the success in preventing campaigns of other gynecologic cancers, such as cervical and endometrial; finally, a silent growing into the abdominal cavity also contributes to diagnostic delay.

Given the strong correlation between prognosis and grade of extension of the disease at diagnosis; early diagnosis should be a cornerstone for management protocols; nevertheless, there is a lack of effective screening tests and a paucity of early diagnosis protocols. In clinical practice, the ultrasonographic diagnosis and characteristics of an adnexal mass determine the necessity of complementary diagnostic procedures and management.

Previous studies focused on a systematic gynecologic scanning program for early ovarian cancer detection raised questions about the effectiveness of this screening protocol. Campbell and Andolf performed 6280 abdominal scans followed by 382 surgeries to detect only five carcinomas. Kurjak, van Nagell, and Bourne obtained similar results in 3905 patients finding 11 carcinomas but requiring 134 laparotomy procedures. ${ }^{1}$

A key issue for an adequate ultrasonographic screening of ovarian masses is the efficacy in the differentiation of benign vs malignant images. Our group is convinced that an experienced sonographer, on the basis of their skill and own subjective impression, could correctly determine the character of a benign or malignant adnexal mass and, in numerous circumstances, may also refer an approach to the histological nature. However, a high image quality in the evaluation of the ovarian mass has the potential for increasing the diagnostic performance of even young sonographers.

Some recent articles have showed that experienced sonographers achieve sensitivities and specificities regarding malignancy of $>95 \%$ and of $>90 \%$ respectively, ${ }^{2}$ and also very high sensitivity in the diagnosis of nonmalignant adnexal masses. Nevertheless, serous cystadenomas were misdiagnosed in up to $40.5 \%$ of cases. ${ }^{3}$

Less experienced sonographers could be helped by scoring systems or mathematical models. Previous studies described a variety of ultrasonographic scoring systems alone (elegantly described by Finkler, Kurjak, 
Granberg, Sassone, De Priest, Lerner, Ferrazzi and Merz) or in combination with vascular Doppler or tumor marker evaluation (essentially CA-125) ${ }^{1,4}$ None of these descriptions-including the most recent ones ${ }^{5,6}$ includes the evaluation of optimal sensitivity/specificity values. Finally, international study groups have described ultrasound-based prediction models to evaluate ovarian tumors (International Ovarian Tumor Analysis-IOTA), nevertheless, its clinical worldwide application by general practitioners remains to be fully tested..$^{7-9}$

Recently, Hata et $\mathrm{al}^{6}$ have described a combination of modern three-dimensional (3D) ultrasound and 3D power Doppler (3DPD) ultrasound as well as quantitative 3DPD histogram analysis, for the assessments of the vascularization and further categorization of adnexal masses. The addition of vascular analysis to the standard ultrasonography is not a novel concept; conventional two-dimensional (2D) sonographic Doppler was first described by Kurjak et al in early 80 's, ${ }^{7}$ this technique paved the way toward new perspectives in the evaluation of vascularity and vascular flow. ${ }^{10-12}$ The 3D sonographic Doppler-introduced 25 years from now and the angio power Doppler enhanced image quality, which was nicely illustrated in several publications ${ }^{13-33}$ (Figs 1 and 2). Doppler scans are nowadays routinely employed in gynecological consultation. ${ }^{13-18,34-45}$

The aim of the present article is to explore state-ofthe-art 3D ultrasound modalities as clinical tools in the differentiation of benign and malignant ovarian masses.

\section{THREE-DIMENSIONAL ULTRASOUND STATE- OF-THE-ART VISUALIZATION MODES}

Image quality is a key-factor to discriminate the origin, location and extension of an ovarian mass, especially when these involve complex structures. Clearer images and elimination of redundant structures and artifacts allow better understanding of the region of interest. The High Definition live (HDlive) technology is a novel ultrasound technique that improves the 3D sonographic images. HDlive uses an adjustable light source and software that calculates the propagation of light through surface structures in relation to the light direction.

The virtual light source produces artificial illumination, and the shadows created by the structures where the light is reflected are depicted. This combination of light and shadows increases depth perception, and produces remarkable photo-like images than those obtained with classic 3D ultrasound. The virtual light intensity can be moved, and the focus changed until the best image is achieved. When the light source is positioned behind the region under study, the effect of maximal translucency can be obtained. ${ }^{10-15}$ Several publications underline its utility in the obstetric field, nevertheless HDlive has been also explored in the gynecological field. For the purpose of the present study, HDlive may add better and more naturallooking images, better and enhanced depth perception, and importantly, a clearer vision of internal tumor structures (papillary projections, septations, cyst walls, etc.).

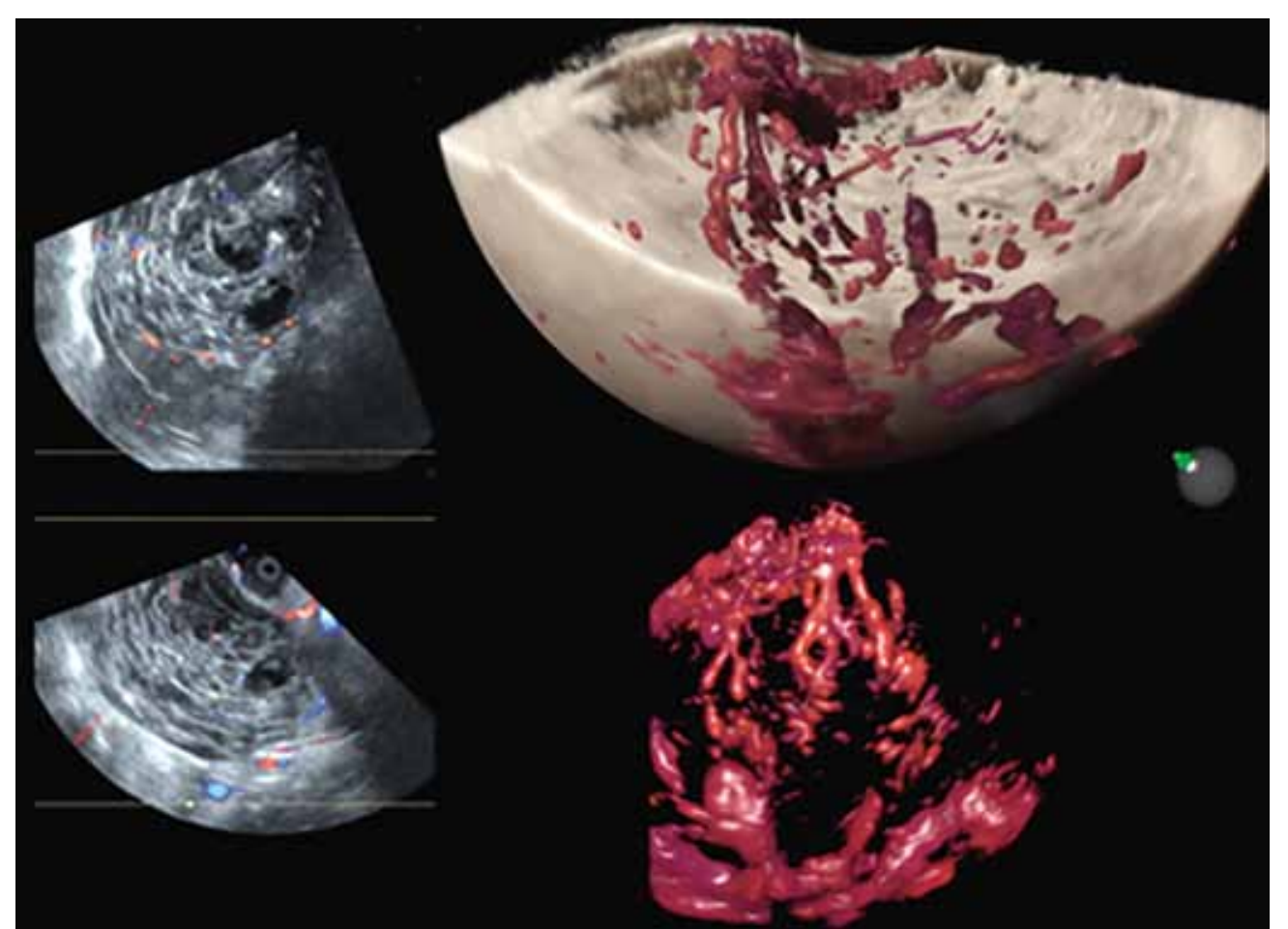

Fig. 1: The two-dimensional angio Doppler (left) and three-dimensional angio power Doppler (right) of a solid ovarian cancer with a fantastic view of its tumoral vascular tree 


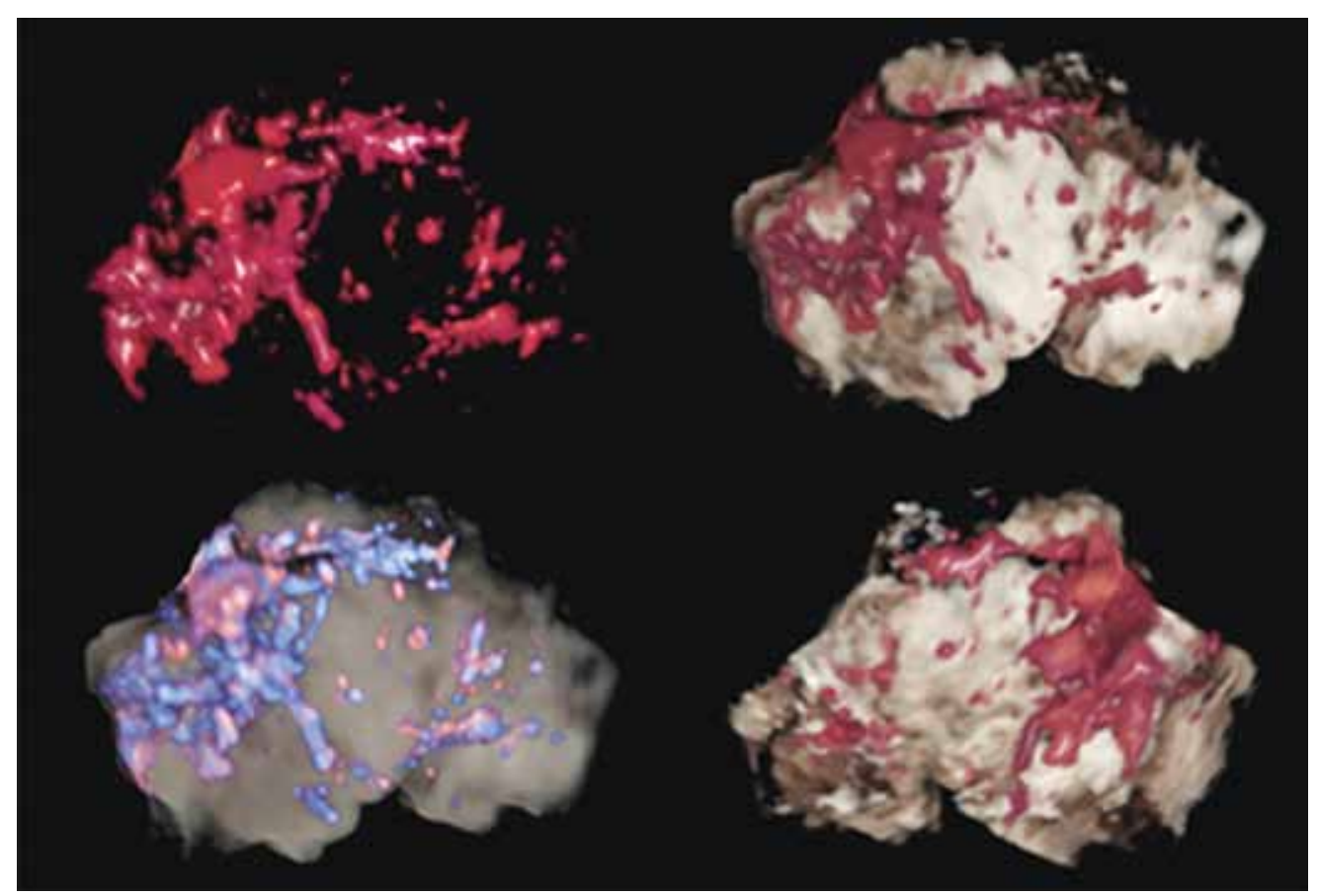

Fig. 2: Three-dimensional angio power Doppler (3D APD) using color Doppler (red and blue colors, left), Doppler energy (red color, right) and isolated angio Doppler (red color, upper left). The entire vascular tree is observed cruising the ovarian tumor. The images are of excellent quality, nevertheless today are well known that the addition of 3D APD does not provide additional information or further improve diagnostic performance

\section{Radiance System Architecture (RAS) or Silhouette}

This extremely modern technique describes a physicallybased rendering system tailored to demands of lighting design and architecture. The simulation uses a light-backwards ray-tracing method with extensions to efficiently solve the rendering equation under most conditions. This includes specular, diffuse and directional-diffuse reflection and transmission in any combination to any level in any environment, including complicated, curve geometries. The simulation blends deterministic and stochastic ray-tracing techniques to achieve the best balance between speed and accuracy in its local and global illumination methods. ${ }^{44-48} \mathrm{We}$ tried to obtain more physical basis information with GE Healthcare (Kretztechnik, Zipf, Austria) but it has been impossible.

\section{HDLIVE AND RAS OR SILHOUETTE IN THE DIAGNOSIS OF OVARIAN MASSES}

An important clinical management in order to improve any early diagnosis in ovarian cancer by ultrasonography should begin by differentiating a group of benign tumors and physiologic structures that can be easily confused with ovarian cancer.

This includes endometriomas (Figs 3 and 4) which are easily identified, has typically gray, homogenous and echoic content; benign teratomas ${ }^{10}$ which have a pathognomonic feature known as the Rokitansky papillae (calcic content within the tumor) along with rest of hair, sebaceous material, and importantly a complete absence of vascularization (Figs 5 to 7).

Physiologic formations (developing follicles, hemorrhagic follicles, and corpora luteum) show an enhanced vascularization, for this reason they could be mistaken as malignant conditions if the actual scoring systems were applied.

Since pioneering publications, ${ }^{1}$ the criteria for categorizing benign $v s$ malignant characteristics of ovarian masses has remained unchanged, only the visualization and the image quality has improved over time.

- Solid and homogeneous tumor component (mainly benign) is the typical image of fibroids for instances (Fig. 8).

- Solid and nonhomogeneous tumor component (mainly malignant) (Fig. 9).

- Pure cystic content (always benign) (Fig. 10).

- Cystic tumor component with small solid components or papillae. Figures 11 to 15 provide examples of the evaluation of internal surface of cystic tumors. Figures 14 and 15 show small papillary projections, highly suggestive of malignancy if evaluated using 2D sonography. However, under HDlive evaluation although irregular in shape, the surface of this projection is smooth and homogeneous, suggesting a benign finding (Figs 11 to 13). HDlive and RAS or silhouette are able to offer a clear evaluation of the internal components tend to rule-out endophytic lesions (Figs 11 to 15). 


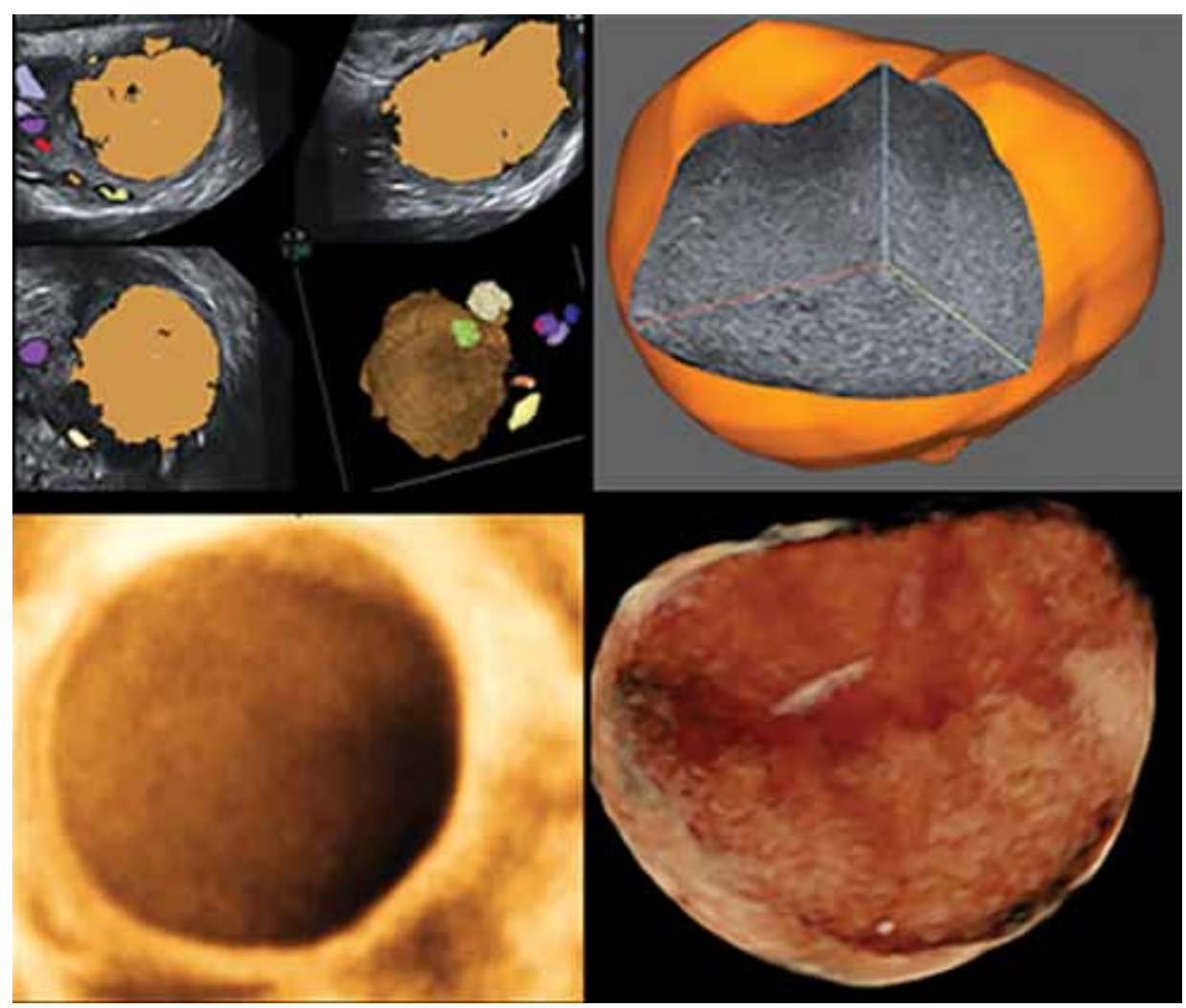

Fig. 3: Endometriosis: A typical image of gray and homogeneous echoes with a complete absence of vessels. Upper left: In brown, an ovarian endometrioma and antral follicles. Upper right: Niche mode, bottom: endometrioma in HDlive reconstruction

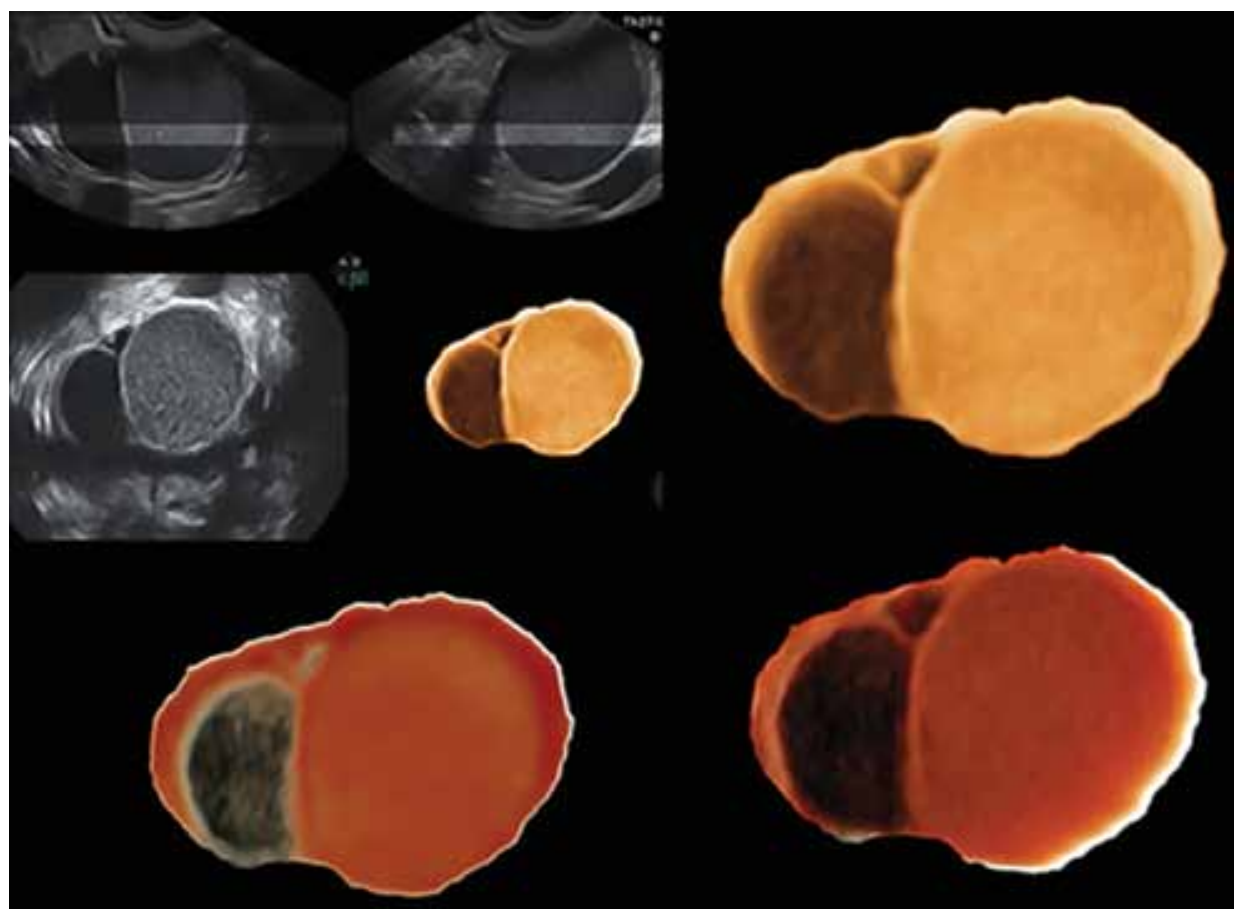

Fig. 4: Typical eco-gray endometrioma depicted with three-dimensional ultrasound and HDlive, showing a simple echonegative follicular cyst at the left of endometrioma

- Cystic multiseptated homogeneous tumor component (mainly benign) - HDlive is shown to be very useful in differentiating this type of masses; when compared to $2 \mathrm{D}$ ultrasound, it becomes easier to differentiate between cystoadenomas from cystoadenocarcinomas as shown in Figures 16 and 17.
- Cystic multiseptated nonhomogeneous tumor component (mainly malignant) (Figs 18 to 21).

- Cystic multiseptated irregular and heterogeneous tumor component (mainly malignant) (Fig. 22). HDlive and silhouette mode add information regarding the shape of the intratumoral cystic walls 

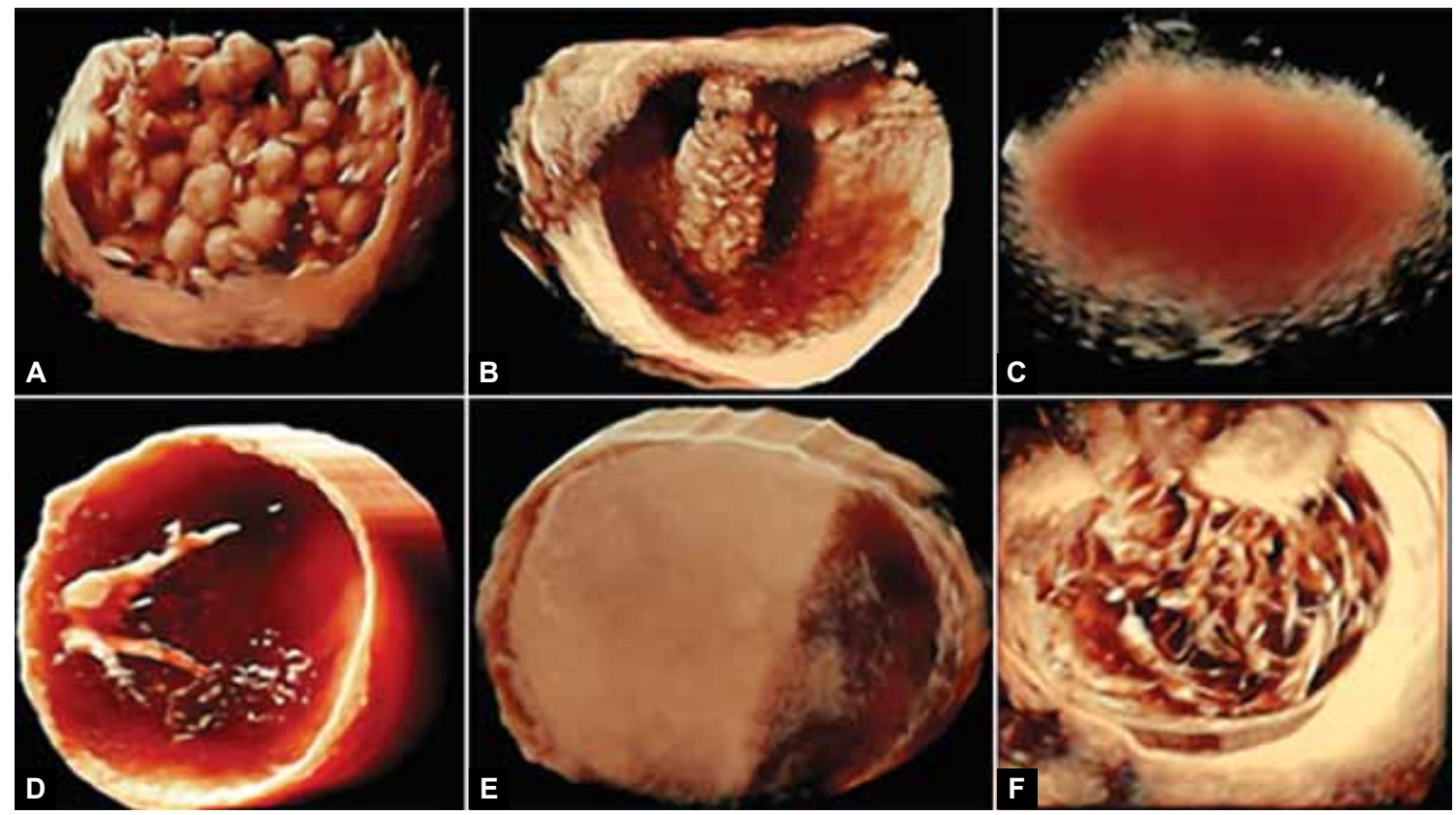

Figs 5A to F: Different types of benign teratomas: (A) Sebaceous balls, (B) Rokitansky papilla, (C) sebaceous teratoma, (D) teratoma 'mash' including hair, (E) a 'two-level' type and (F) mix type, a complex teratoma showing hair, sebaceous tissue and papillae

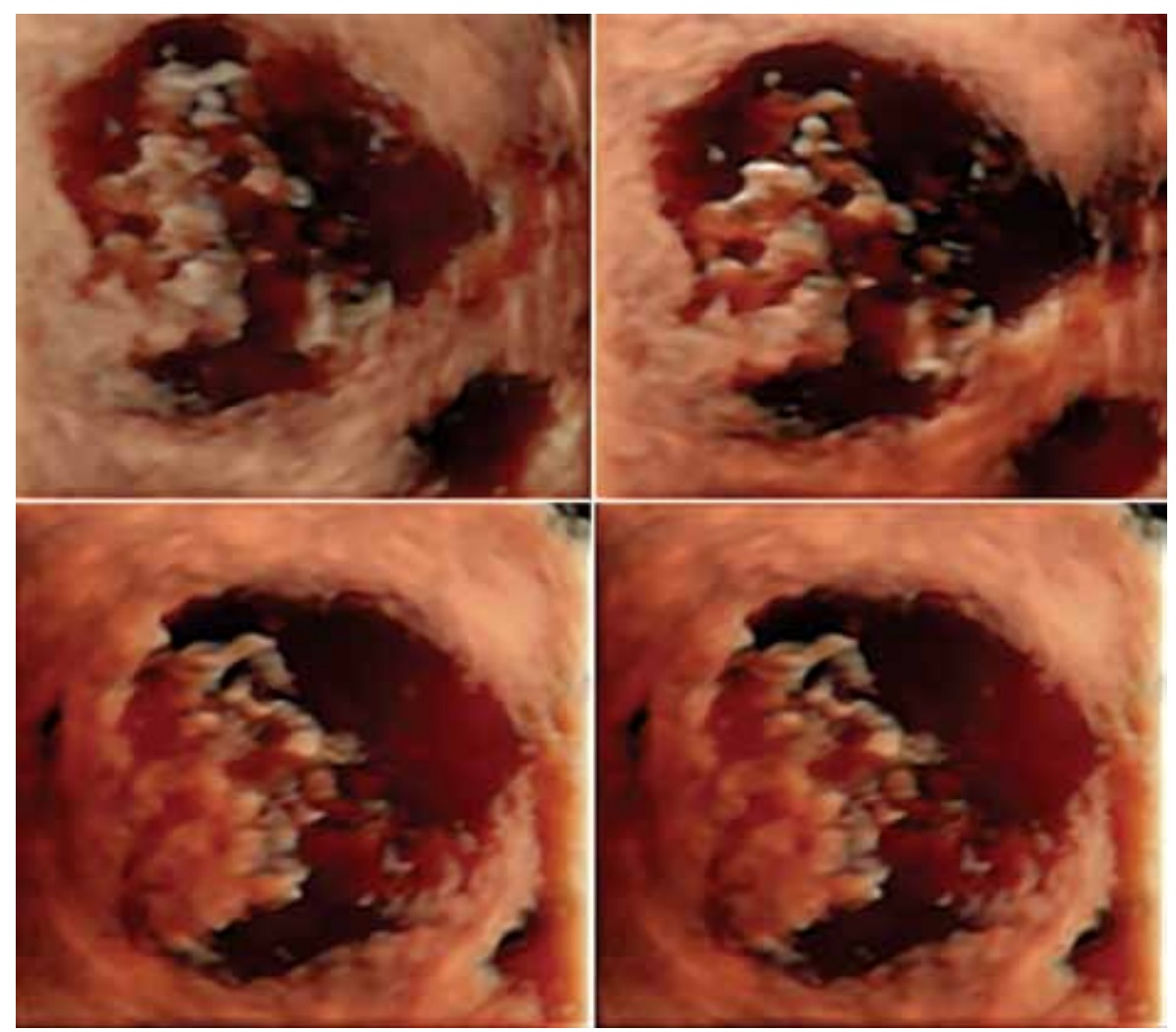

Fig. 6: HDlive image in different light angles and intensities showing an ovarian benign dermoid tumor with numerous small calcified spots adopting the aspect of a cauliflower

(septations, and the presence of papillary projections). See Figure 18.

- Mixed (solid-cystic) tumor component (mainly malignant). This typical finding of malignancy is related to an expansive development of a part of the tumor, whereas some other areas develop degeneration or necrosis (Figs 17 and 20).
The presence of septations and papillae should be clearly observed and described, since they are of enormous help in the differentiation of benign $v s$ malignant process. Thin and homogeneous septations are always related to benign tumors (Figs 23 and 24).

The presence of papillary projections is usually correlated to malignancy when HDlive software is used. Even 


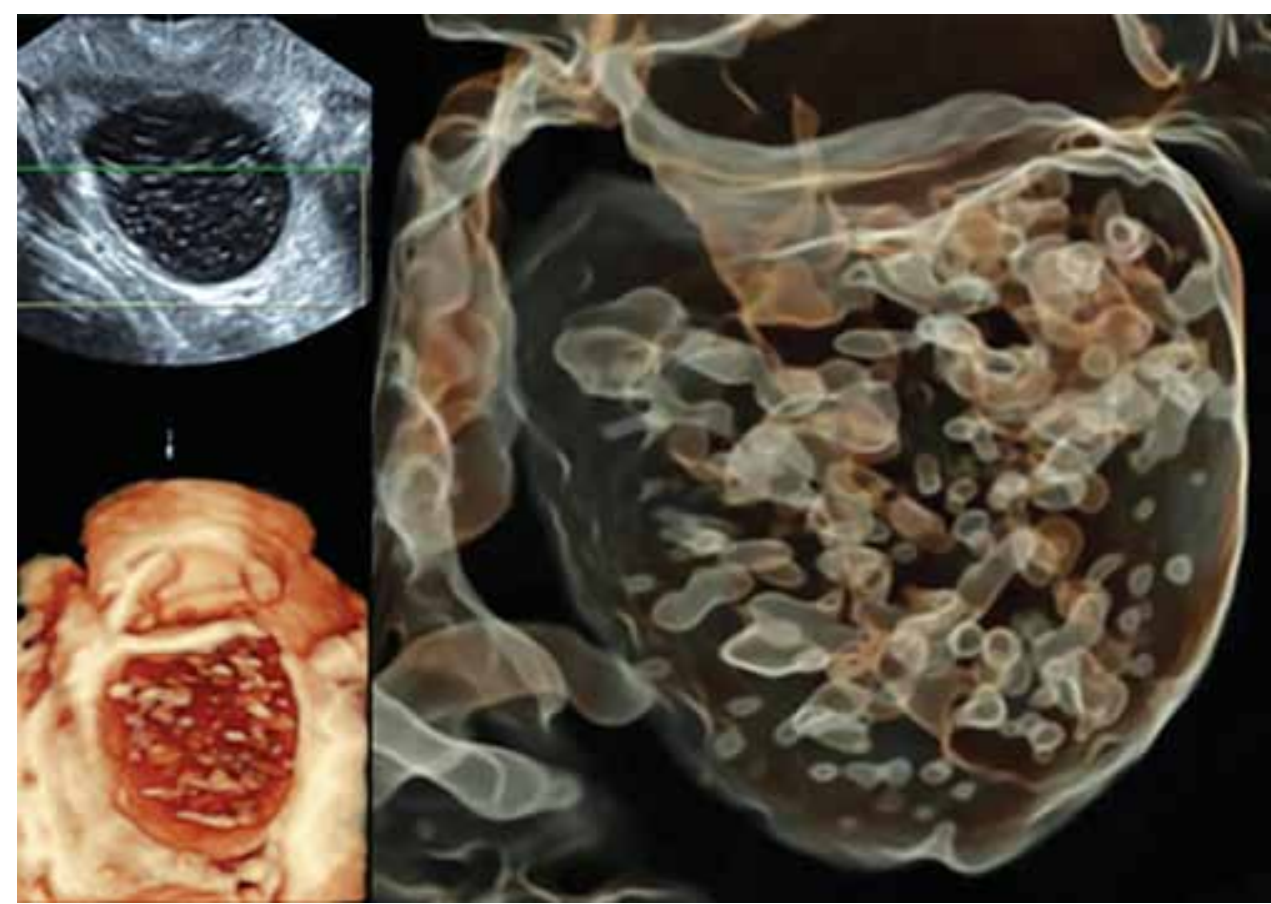

Fig. 7: Left: HDlive image of a 'mesh' teratoma containing hair and sebaceous tissue. Right: radiance system architecture image of the same tumor. Notice the clear definition of the internal structure limits (hair)
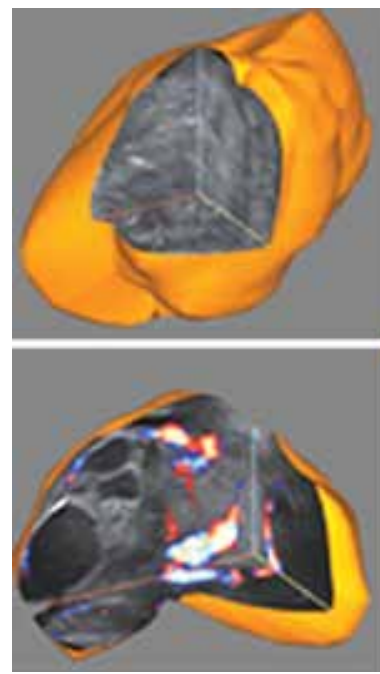
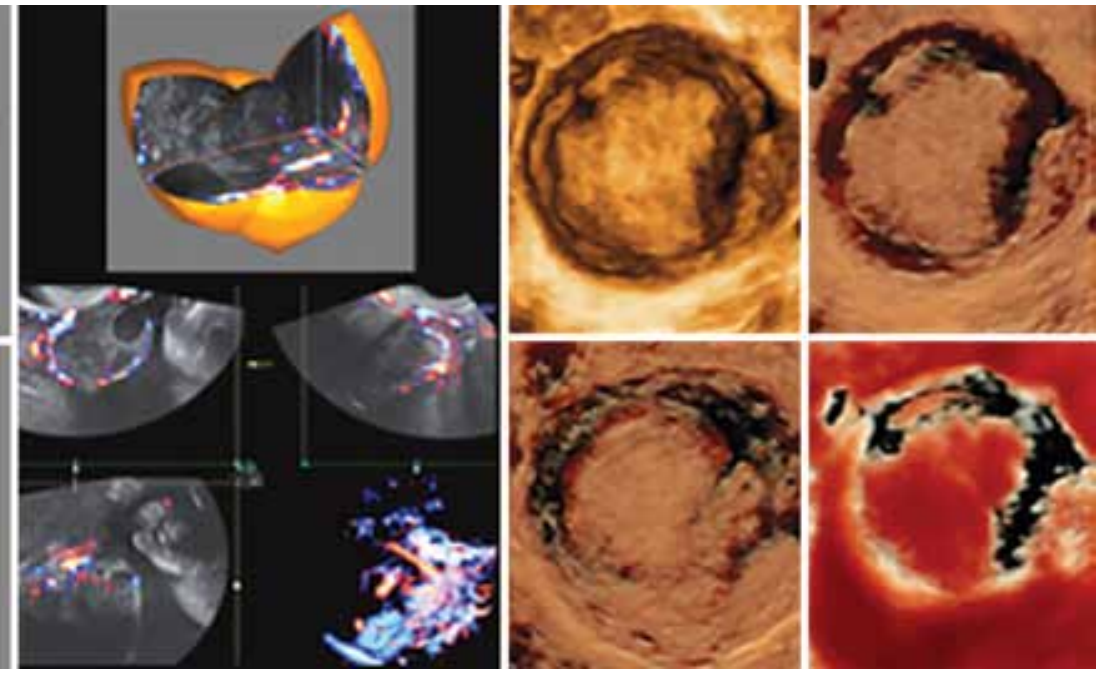

Fig. 8: Three-dimensional 'shell' or niche image of a solid ovarian tumor with abnormal vascular component, typical of malignancy (to the left). HDlive visualization of an ovarian mass shows an almost complete solid component. Bottom right: maximum transparency view. The heterogenous component and the presence of papillary growths in the periphery highly suspicious of malignancy are clearly depicted (to the right)

small and irregular papillae can be clearly studied, and the image obtained is superior to what is usually depicted by $2 \mathrm{D}$ sonography (Figs 13, 14 and 18 to 25 ). Some other features related with malignancy can be analyzed in-deep by HDlive and RAS, including increased thickness (more than $3 \mathrm{~mm}$ ), irregularities of the cyst wall (Figs 17, 18, 20, 25 and 26), cyst wall rupture (Figs 5 and 15), and the presence of ascites and metastasis.

Presence of papillary projections (malignant) (Figs 12, $13,19,26$ to 28). These fluid-filled cysts with gray color are different from those with low intensity of endometriomas (Figs 26 and 27). This liquid corresponds to the serum of a cystadenocarcinomas. They are always a sign of malignancy as well as appearance of papillae, pathognomonic for malignancy.

When studied in HDlive, these growths are marked clearly much better than $2 \mathrm{D}$, and papillae are small with very irregular shapes.

- Tumoral wall thickness bigger $>3 \mathrm{~mm}$ (malignant) (Figs 16 to 19 and 28)

- Irregularities in the tumor wall or irregularities of the proper tumor wall (malignant) (Fig. 28)

- View of the wall rupture (mainly malignant). Although benign ovarian tumors (such as cystoadenomas, etc.) can produce wall rupture, this phenomenon is much frequent and characteristic of malignancy. 


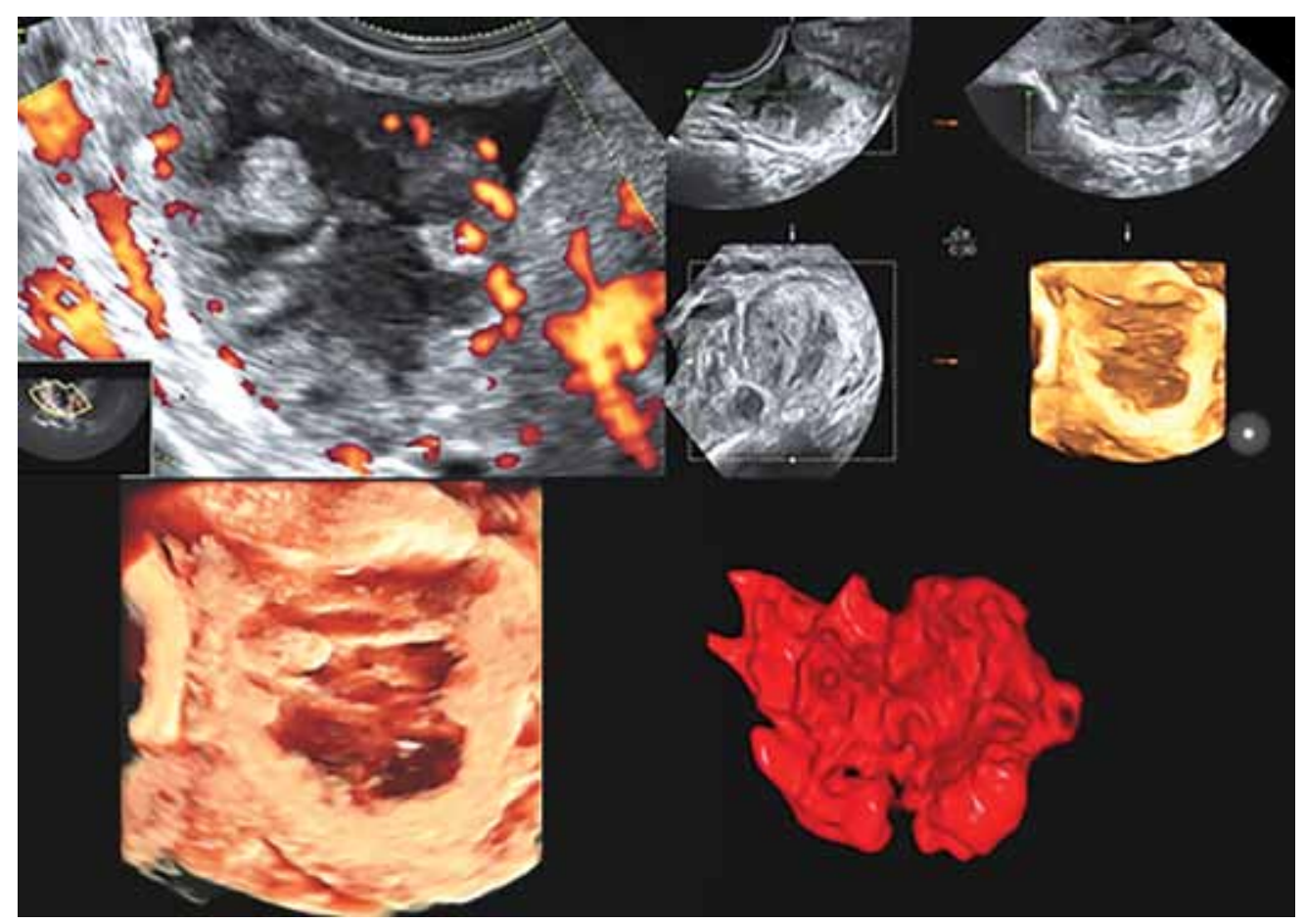

Fig. 9: Two-dimensional Doppler energy (above left), three-dimensional sonographic (above right), HDlive visualizations, and automatic volume calculation (below right) of a nonhomogeneous mainly solid ovarian mass. The heterogenous component and the presence of papillary growths in the periphery are highly suspicious of malignancy, and are clearly depicted

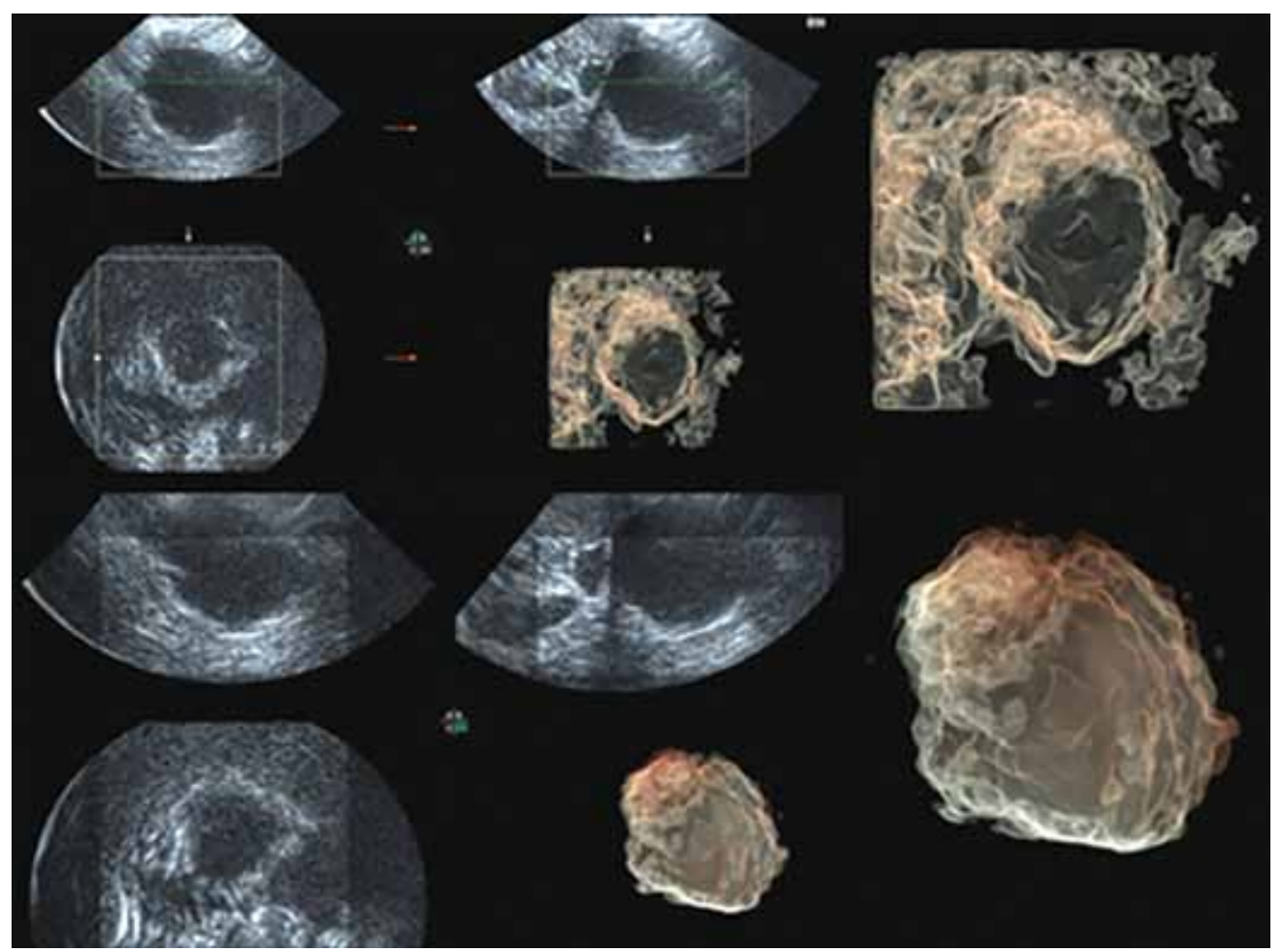

Fig. 10: Left: orthogonal plane view of a 'pure' ovarian cyst. Right: the same structure under radiance architecture system view. Notice the external surface (up) showing adhesions to surrounding tissue and the homogeneous and smooth internal surface (down). This finding is considered benign until a maximum diameter of $5 \mathrm{~mm}$, but in our opinion up to $10 \mathrm{~mm}$, can be considered benign providing the absence of papillary projections and septations

It is not easy to visualize with vaginal 2D US. Can be observed with 3D, but we recommend to use the 'niche or shell' mode (Figs 3, 8, 15 and 27).

- View or appearance of ascites (malignant)

- View of local or liver metastasis (malignant)

\section{CONCLUSION}

Three-dimensional real-time ultrasound has been proved to be better than $2 \mathrm{D}$ sonography in the evaluation of adnexal masses. ${ }^{42}$ This review adds further on the topic 


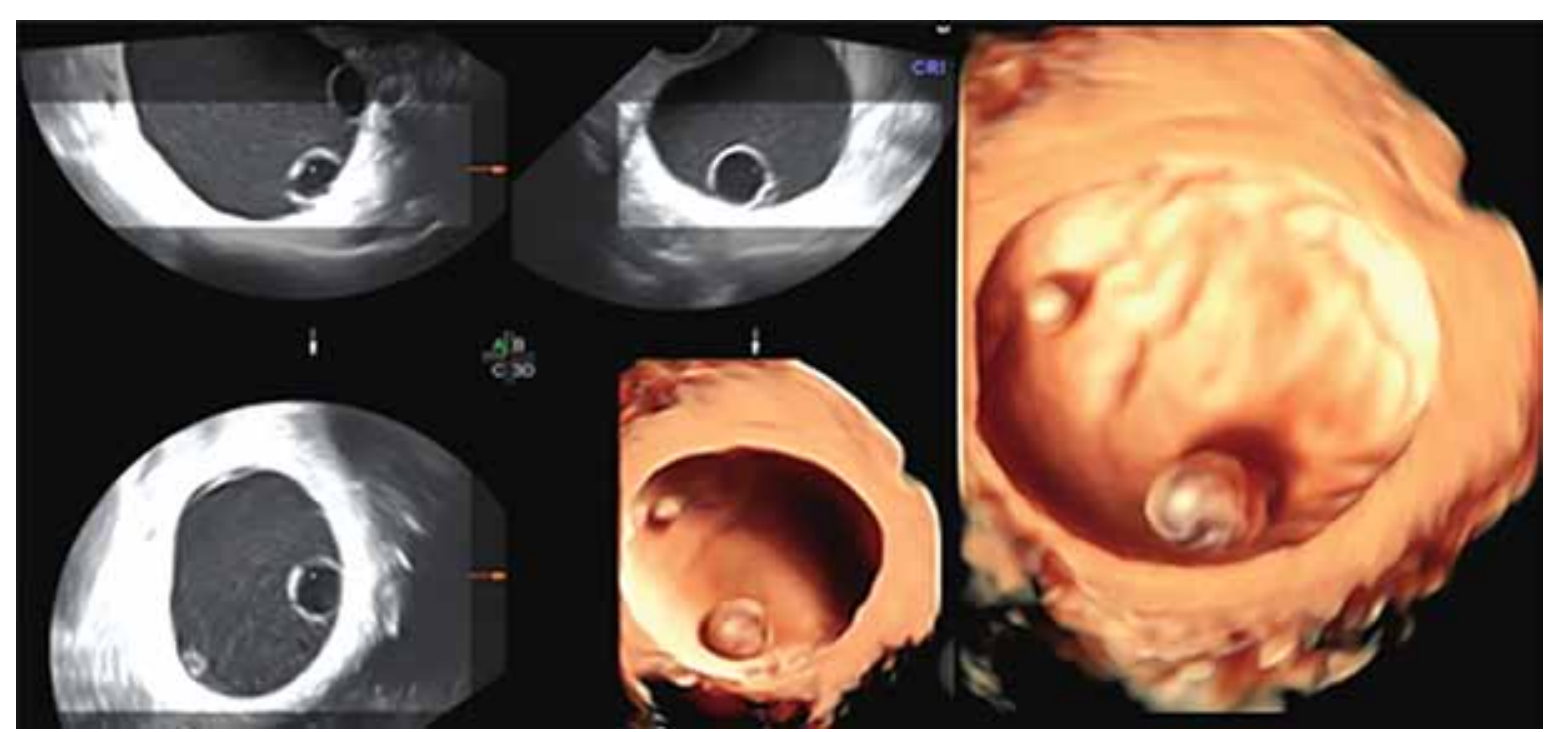

Fig. 11: Cystic formation observed in two-dimensional and HDlive reconstructions. HDlive shows more clearly the inner surface of the cystic mass, which contains two small homogeneous vesicular projections, suggesting a benign pathology

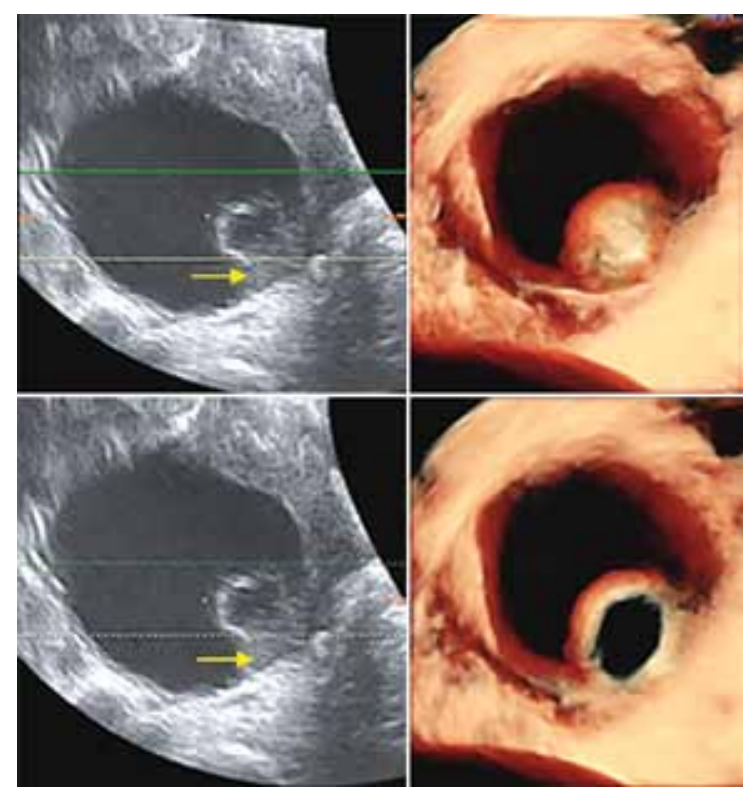

Fig. 12: The two-dimensional ultrasound evaluation shows a small vesicle and a solid implantation base (arrows), both showing homogeneous borders, highly suggestive of benignity

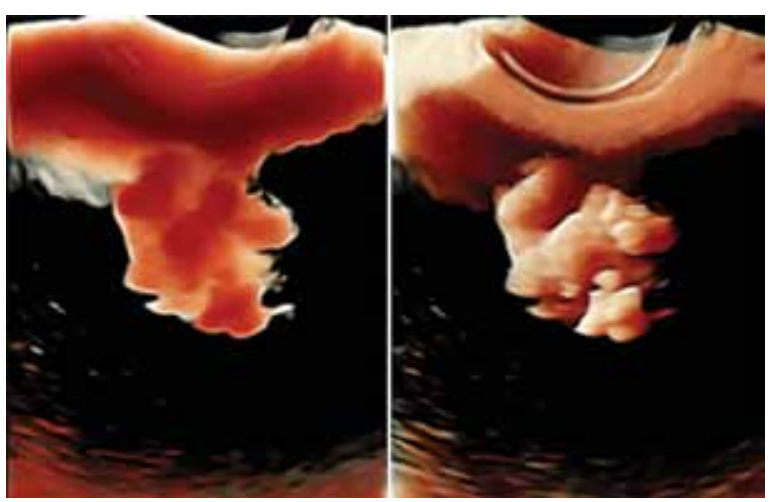

Fig. 14: Close-up view of a small endophytic component within a 'pure' ovarian cyst; although small in size, HDlive shows an irregular and heterogeneous surface with small papillary projections. These features are highly suspicious of malignancy. Compare these findings with the ones in Figures 11 to 13

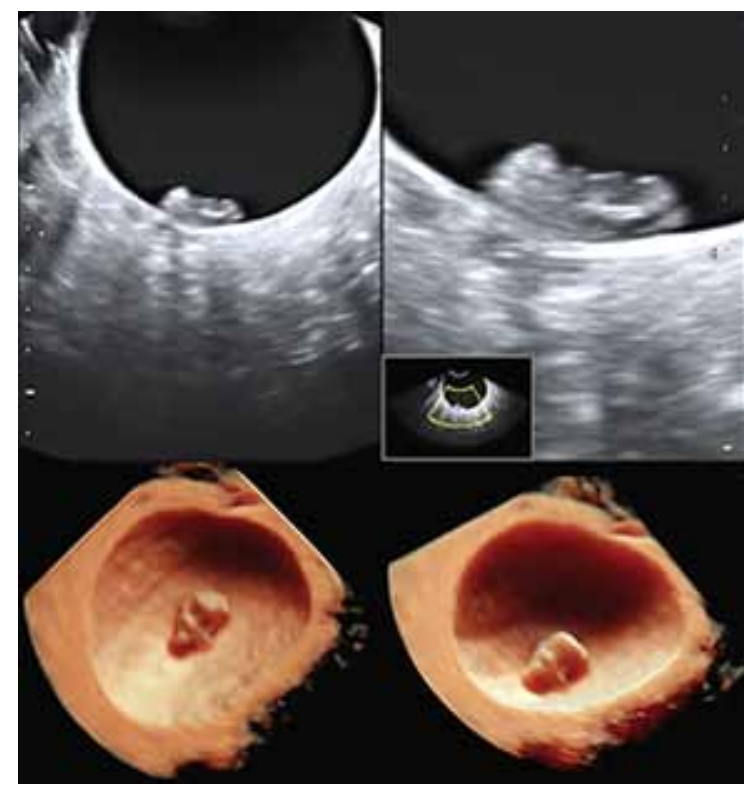

Fig. 13: Above: Two-dimensional image of an ovarian cyst with a small endophytic tumoral component. Bottom: The same ovarian mass under HDlive visualization shows that the endophytic growth has a smooth and uniform surface, thus, benign in nature

by addressing the role of state-of-the-art 3D ultrasound modalities, namely HDlive and RAS, for the assessing of ovarian masses.

Numerous publications describe the use of 2D sonography in the evaluation of ovarian masses.

There are fewer medical publications describing the study of ovarian tumors by 3D ultrasound with or without Doppler. ${ }^{20-26,29-31}$ Nevertheless, it is unquestionable that the image quality and definition of structures are enormously superior with 3D ultrasonography.

HDlive and RAS are innovative tools within 3D ultrasonography; these softwares provide a more realistic vision and definition of ovarian masses. Threedimensional ultrasound and volumetric reconstruction allow a complete virtual navigation throughout the 


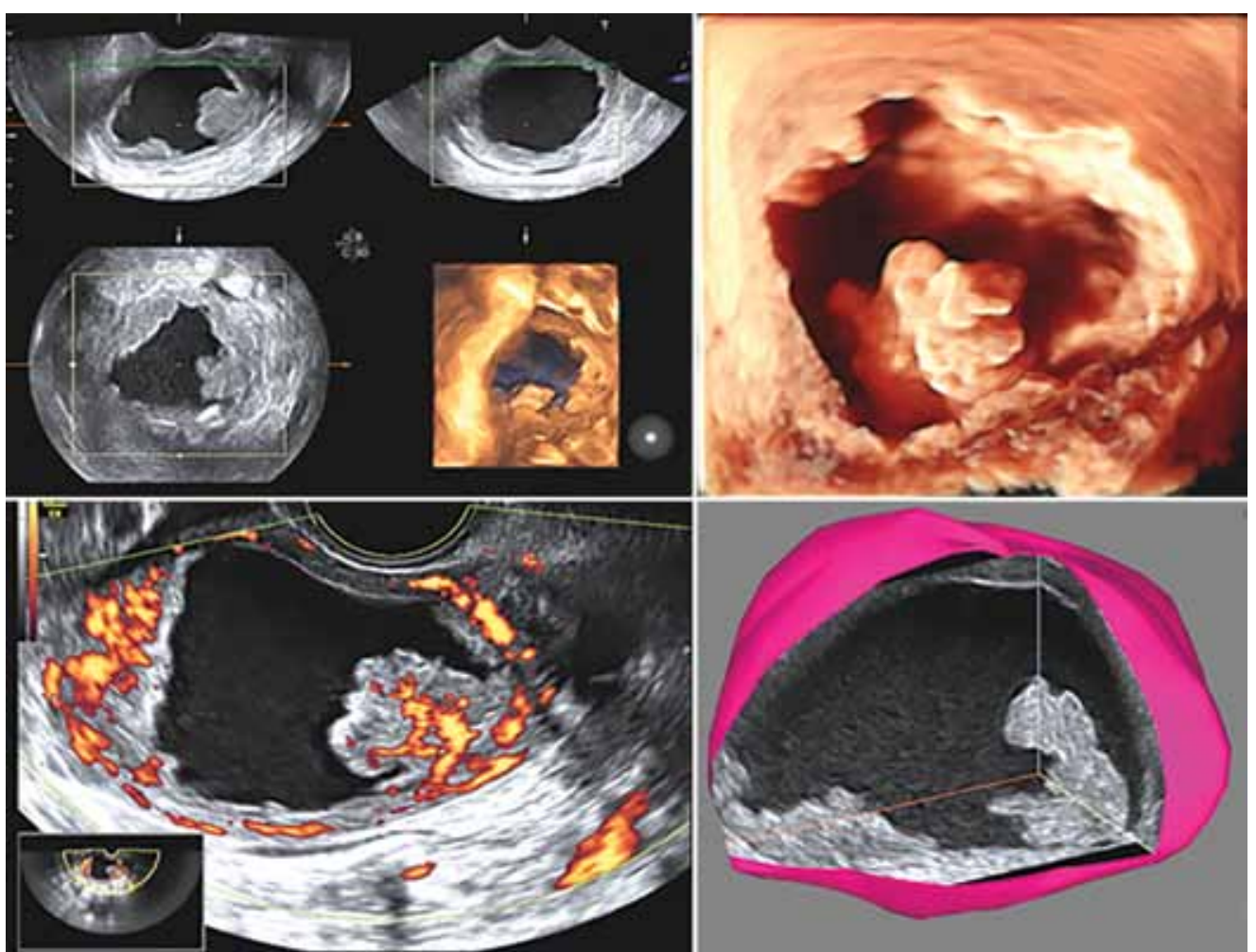

Fig. 15: Cystic ovarian tumor in three-dimensional ultrasound and HDlive reconstructions showing a small papilla extremely vascularized (Doppler energy). Although the capsule is complete (see the 'shell' or 'niche' image, below right in red color), the whole aspect is of malignancy

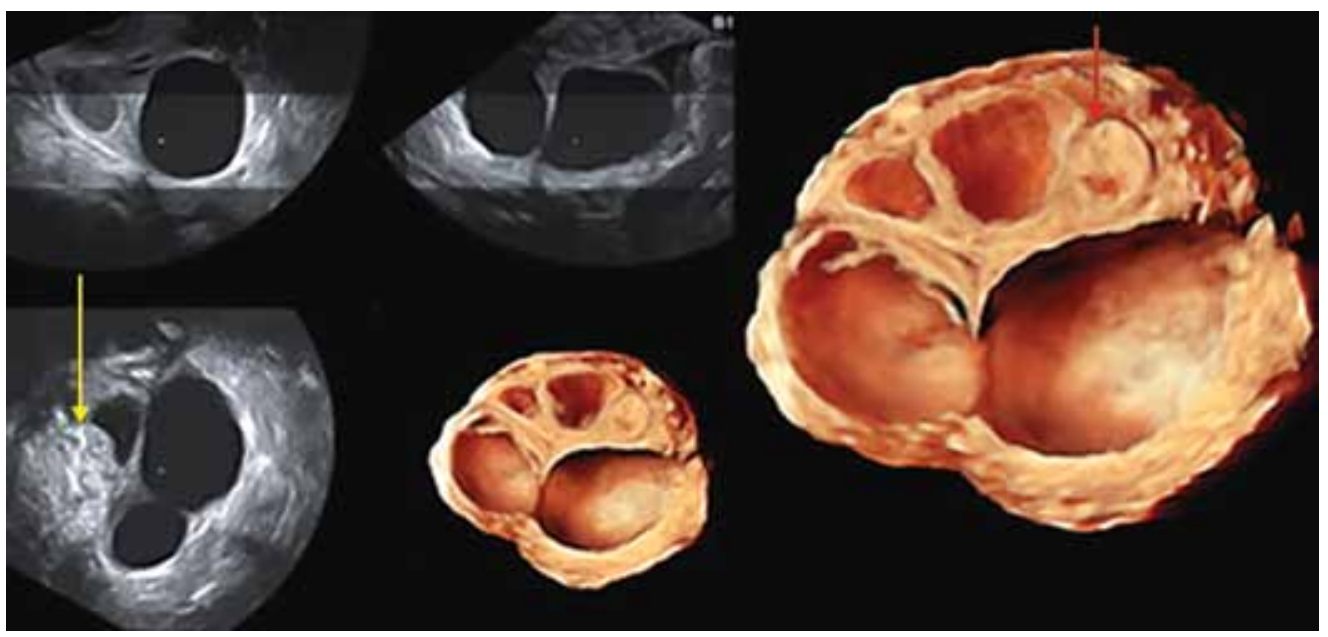

Fig. 16: Multicystic ovarian tumor. Two-dimensional evaluation shows a highly suspicious solid tumoral mass (yellow arrow) adjacent to the cysts. HDlive clearly depicts the inner and external surface of the cysts, showing smooth characteristics of walls and septations compatible with a benign pathology. Moreover, the solid mass seems now more compatible with a corpus luteum under involution. The final pathologic diagnosis was a mucinous ovarian cystoadenoma. Compare with Figure 18

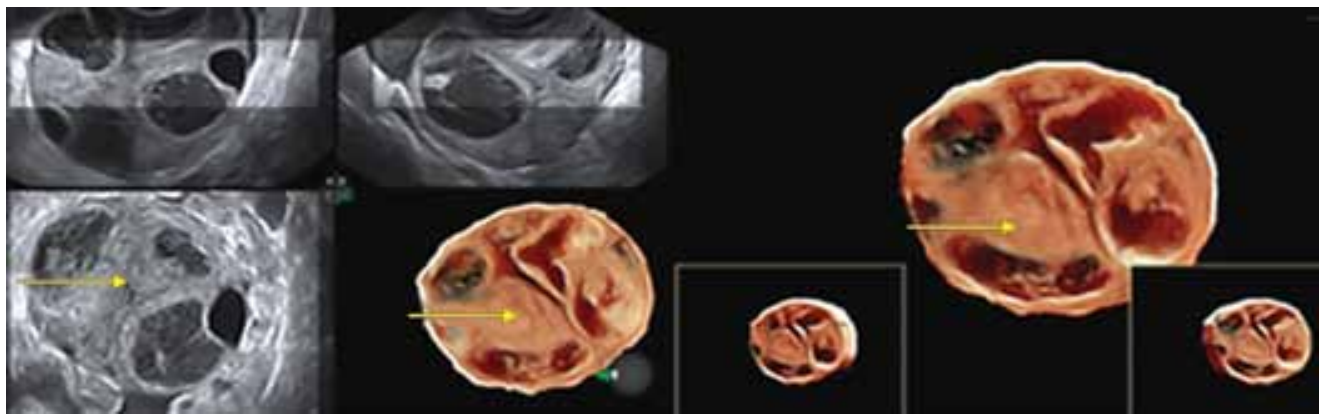

Fig. 17: HDlive image of a mixed (cystic-solid) ovarian mass. The yellow arrow shows a solid, irregular part of the mass. The cystic formations have different size, irregular thickness of the walls, and isolated papillae with endophytic growth 

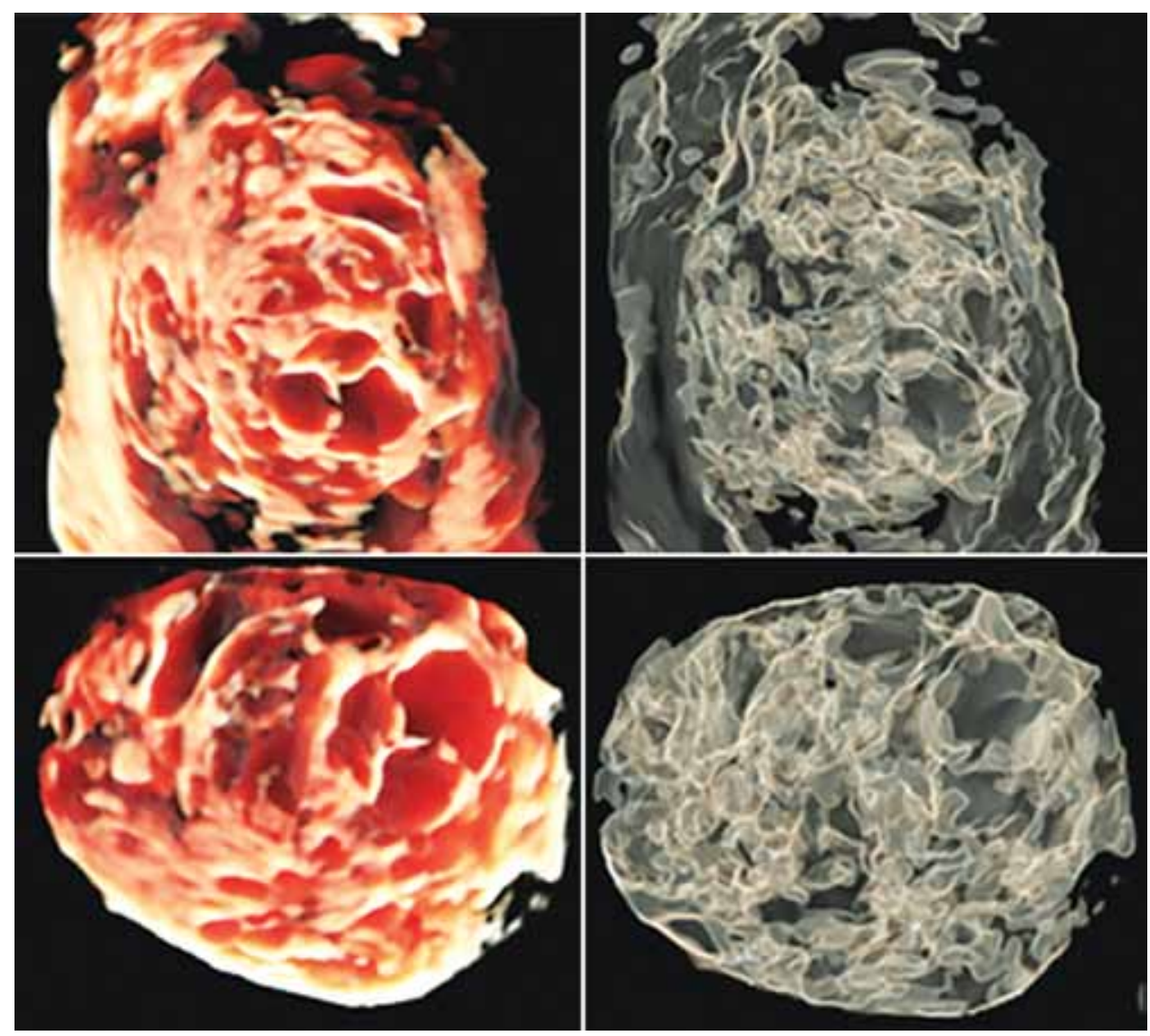

Fig. 18: HDlive and its silhouette mode of an ovarian serous cystoadenocarcinoma. Notice, especially in the silhouette view, the irregular size, shape, and limits of the multiple small cysts. All these findings are strongly suggestive of malignancy

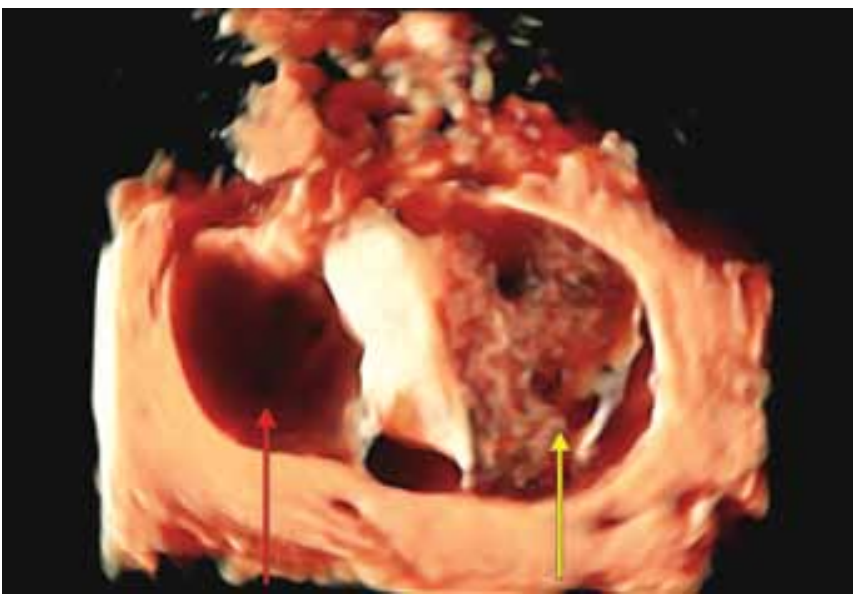

Fig. 19: Cystic multiseptated nonhomogeneous tumor. The left cyst (red arrow) is homogeneous and looks benign. The right cyst (yellow arrow) shows endophytic growth and papillae, very suspicious of malignancy. The septum between the cysts is also thick and amorphous (mainly malignant)

ovarian tissue in the three spatial planes, facilitating a precise evaluation of intratumoral features, such as discrimination of liquid vs solid components, characteristics of papillary projections and septations (if present), and the description of vascular trees (if present) as well as external features, such as tumor diameter, wall thickness, contour and boundaries. Furthermore, this important information is provided through the reconstruction of realistic 3D images.
The current study shows that HDlive and RAS offer unique ways for assessing women with ovarian masses; anatomically realistic images of the region of interest can be obtained with HDlive; and the spatial relationship and boundaries of intratumoral surface structures can be clearly depicted with RAS. Altogether, this information is extremely important to facilitate the differentiation between benignity and malignancy of ovarian masses, and is in agreement with previous publications on the issue. $^{13}$

Obviously, expertise is a key component for achieving a good diagnostic performance; nevertheless, modern $3 \mathrm{D}$ ultrasound modes may facilitate practitioners diagnostic competence and level on confidence by means of providing high quality and great definition images, moreover, the learning curve in trainee programs could be also significantly reduced as suggested by others. ${ }^{43}$

Our publications and much more specifically the one of Hata et $\mathrm{al}^{13}$ have showed that 'HDlive facilitated a more precise evaluation of adnexal tumors and accurate characterization of the intratumoral surface structures'.

In particular, and what is extremely important to increase image quality and so facilitating the differentiation between benignity and malignancy of adnexal masses, HDlive is more definitely showing particularly, 


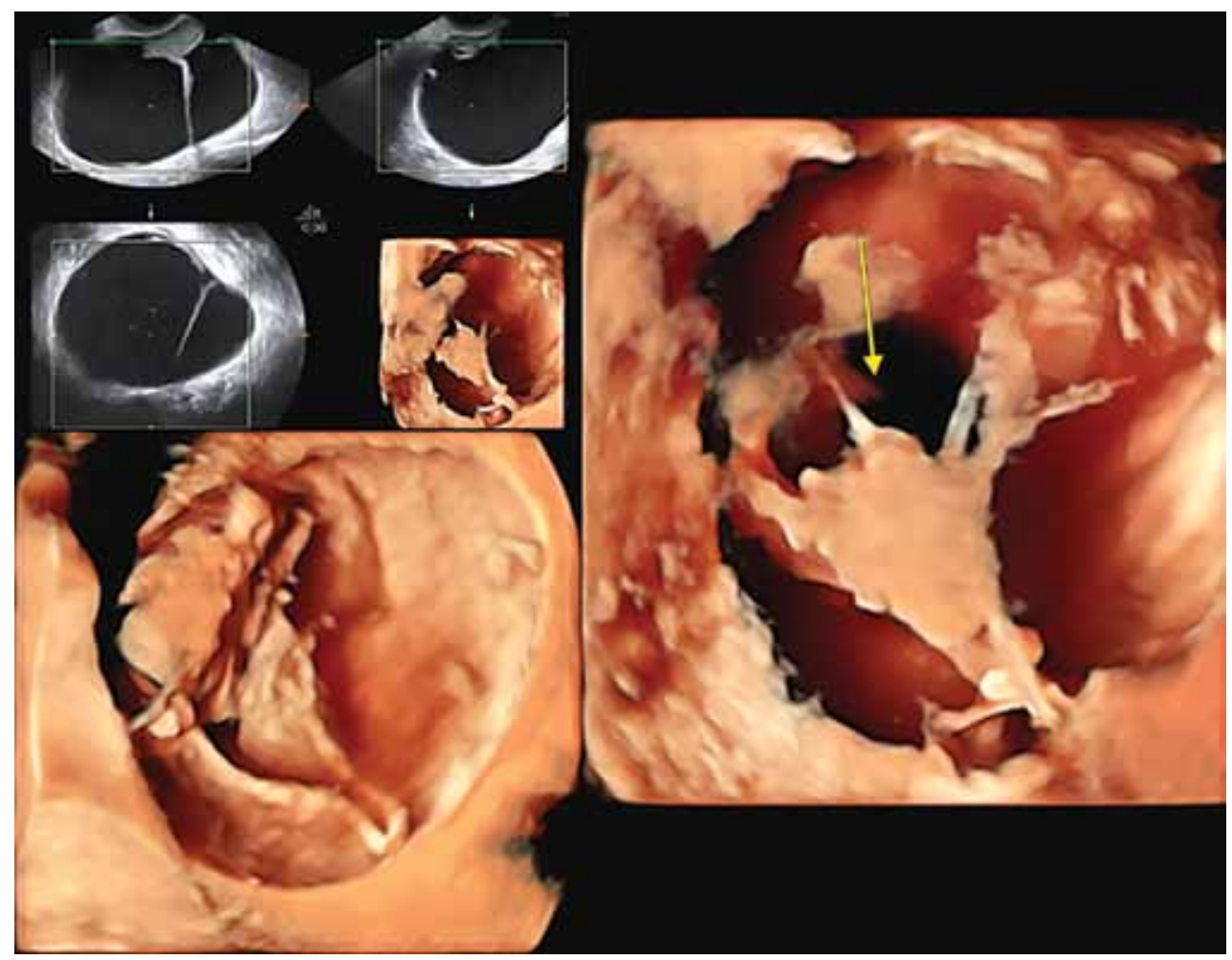

Fig. 20: Ovarian, mainly cystic, malignant tumor. The most interesting tumor part is the one marked with the yellow arrow. It looks like a 'malignant star' full of irregular walls and exophytic papillary projections

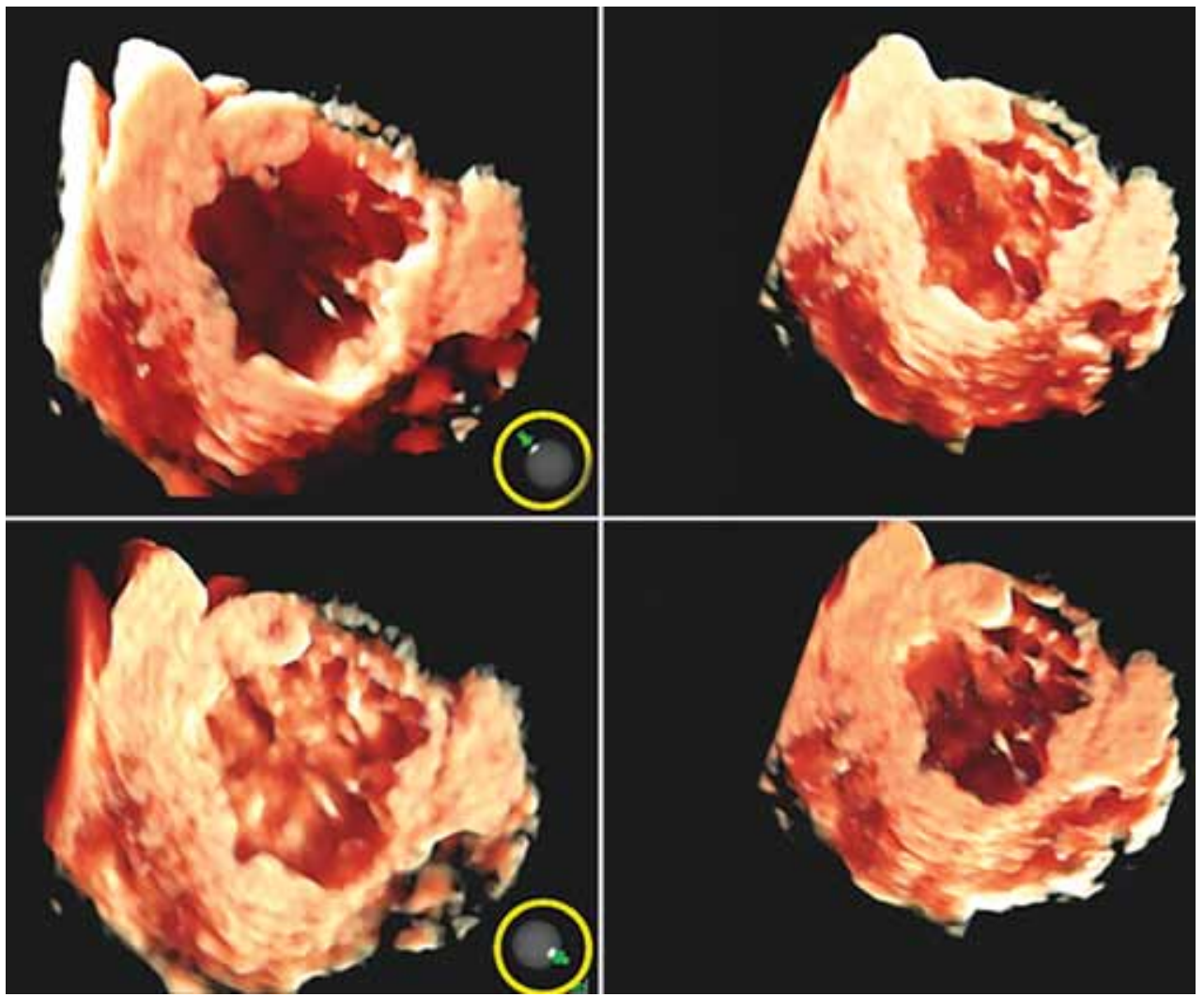

Fig. 21: Cystic, irregular and nonhomogeneous ovarian tumor. Many necrotic parts and papillary growths are visible. The image is totally compatible with malignancy

a natural and anatomically more realistic appearance of the smooth thin or irregular thick septum, smooth or irregular papillary projection, and smooth, regular, or irregular inner surface.
Hata et $\mathrm{al}^{13}$ finally speak about a 'surgeon's eye' view of unique intratumoral anatomic structures 'not easily seen or understood using the conventional 3D sonographic mode'. 

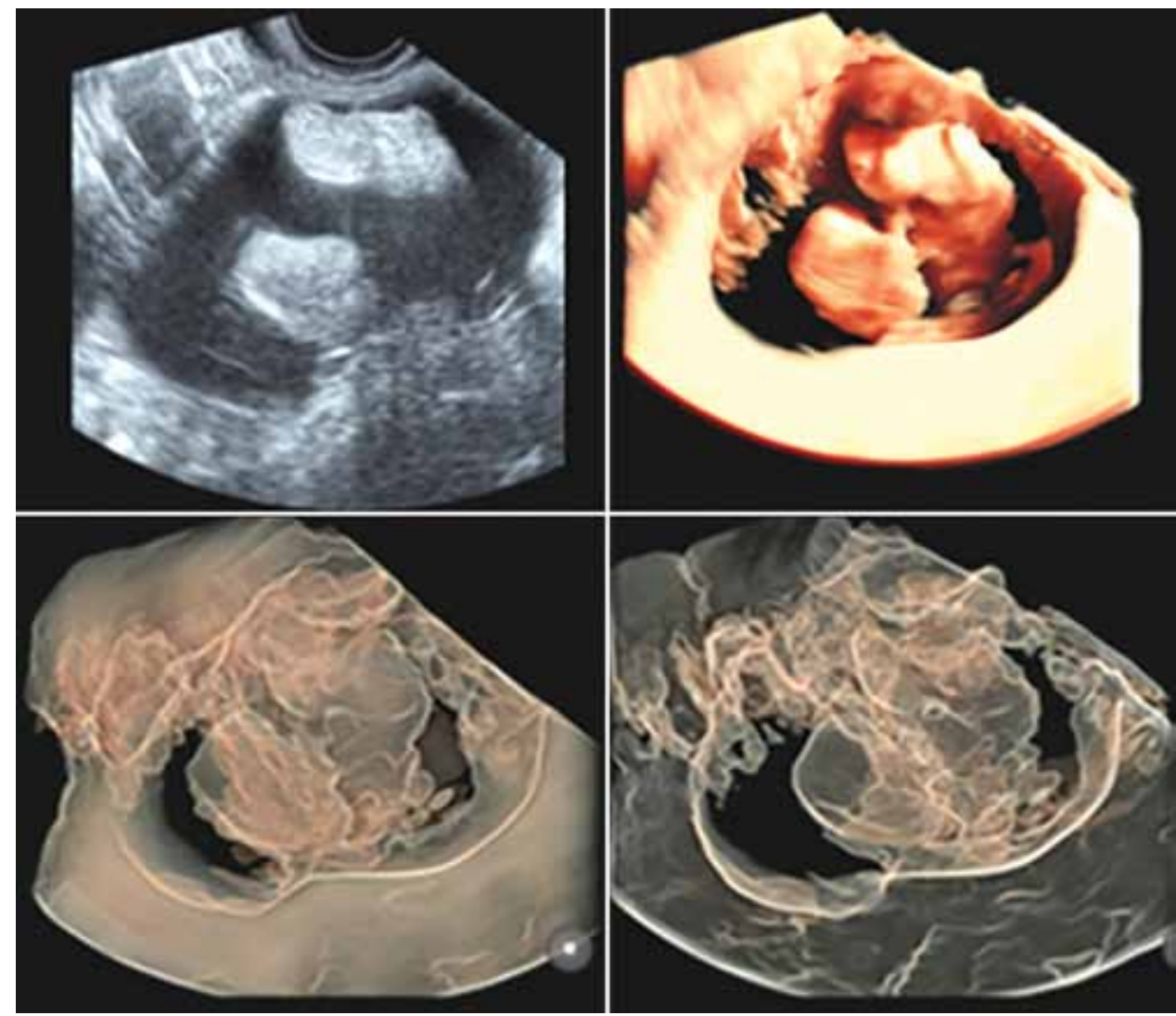

Fig. 22: Comparative images of a heterogeneous solid-cyst ovarian mass. The three-dimensional ultrasound mode shows a higher image quality compared with two-dimensional ultrasound (above). The mixed component, solid-cystic and fluid, showed in the four images is completely amorphous, specially the solid component (HDlive view). The silhouette mode shows clearly the internal and external delimitation of the ovarian mass components. These findings are highly suggestive of malignancy

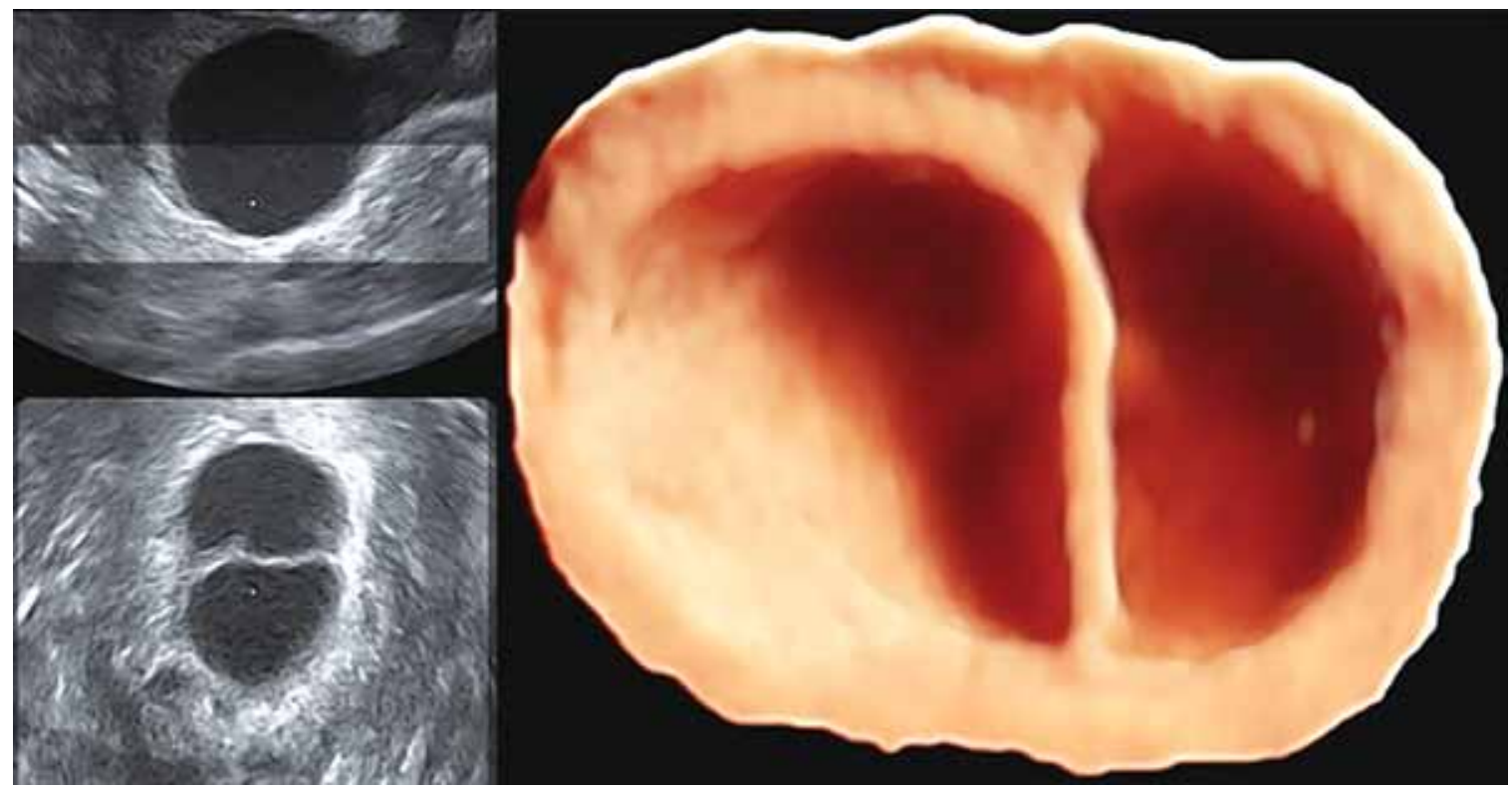

Fig. 23: HDlive view of a pure ovarian cyst. Note the smooth and regular septation suggesting a benign pathology, whereas the findings of thick $(>3 \mathrm{~mm})$ and heterogeneous septations are highly suspicious of malignancy

Summarizing, HDlive, and radiance system architecture or silhouette mode provide a much better vision quality of internal tumor structures, which facilitate the diagnosis.

In conclusion, state-of-the-art 3D ultrasound tools provide specific and essential information for the differentiation of benign and malignant ovarian masses. Thus, this technique may help to improve diagnostic confidence and accuracy for a correct clinical intervention, and has the potential for reducing the learning curve in trainee programs. However, further studies are needed to validate our findings, and to establish its role in clinical practice. 


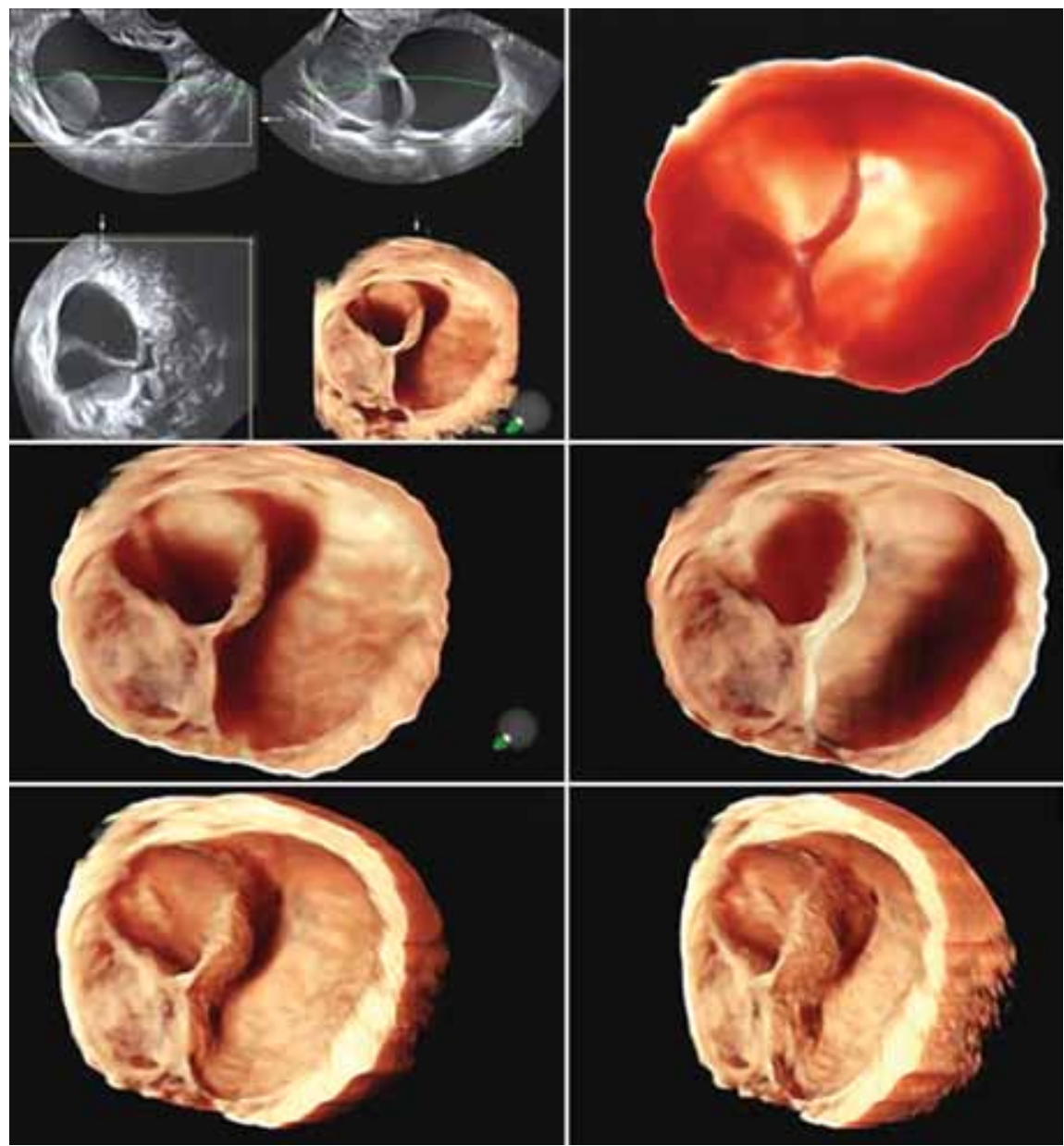

Fig. 24: Ovarian tumor with various cysts of different sizes. All are with fine, homogeneous and septations of same thickness and without endophytic growths. When depicted in different angles and light sources, they are all regular. These tumors are always benign

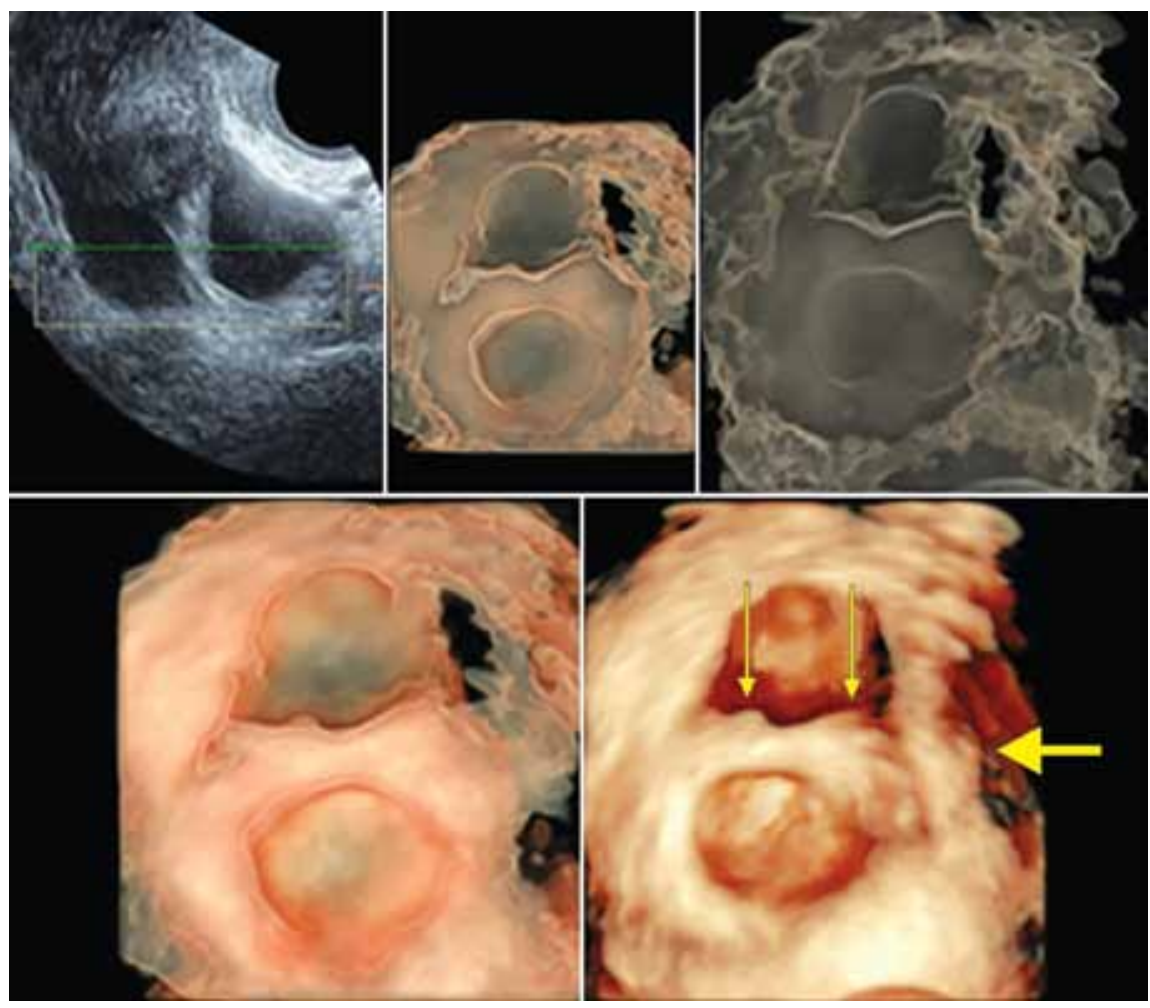

Fig. 25: Two-dimensional (2D) ultrasound (top left), system architecture or radiance silhouette (RAS) (above center and right) and a characteristic HDlive malignant tumor showing septum (bottom right, arrows) minimum papillary projections not visible in 2D ultrasound (top left). When RAS is applied, a clear internal and external delimitations, and tumor boundaries can be observed 


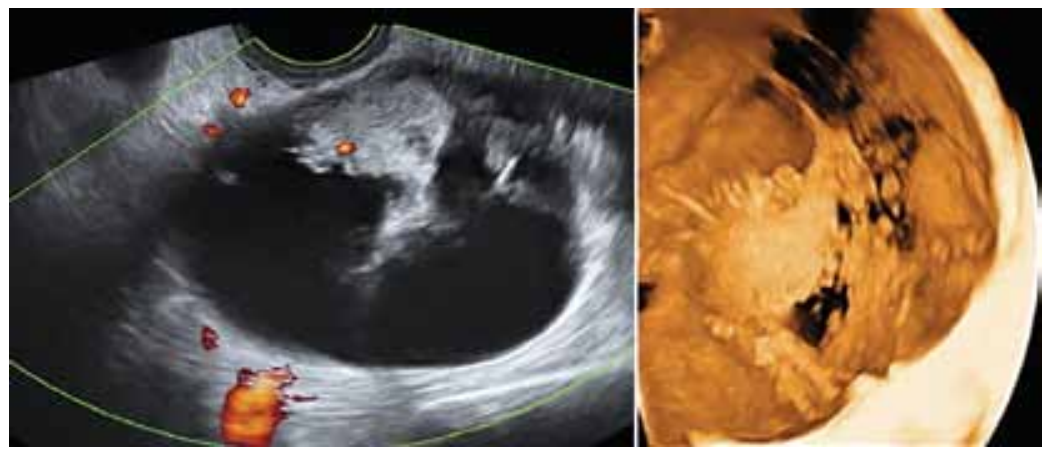

Fig. 26: A solid ovarian tumor area shows numerous septa and irregular, thin and thick walls, larger than $3 \mathrm{~mm}$ and/or in homogeneous. This is very suspicious of malignancy
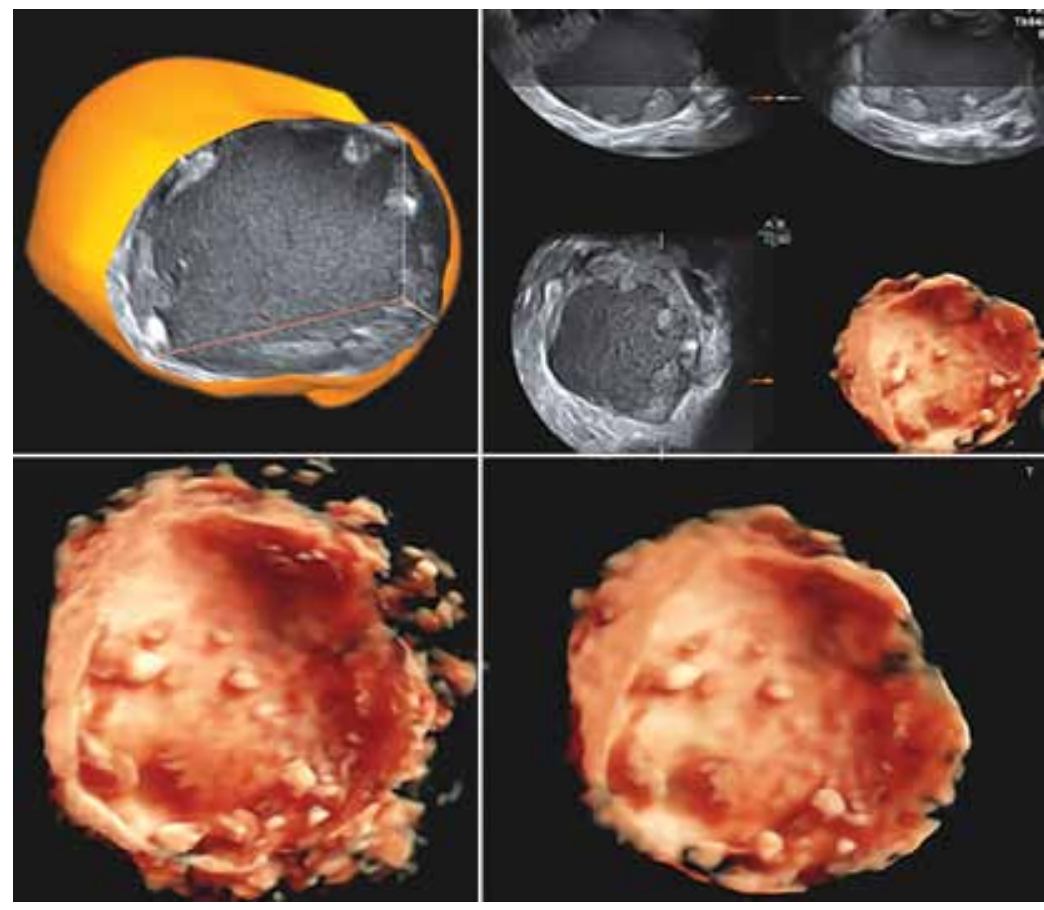

Fig. 27: Small ovarian cancer shows in detail small inner papillary projections, typical of malignancy. Above and left: 'niche' or shell mode showing integral capsula. Below: HDlive showing the inner tumor with small papillae and endophytic growths. Even still few in number, they are specific to tumor malignancy, which means that atypical epithelium is growing. The 'niche' mode is used to demonstrate the integrity of the tumor capsule (see also Figs 3, 8,15 and 27)

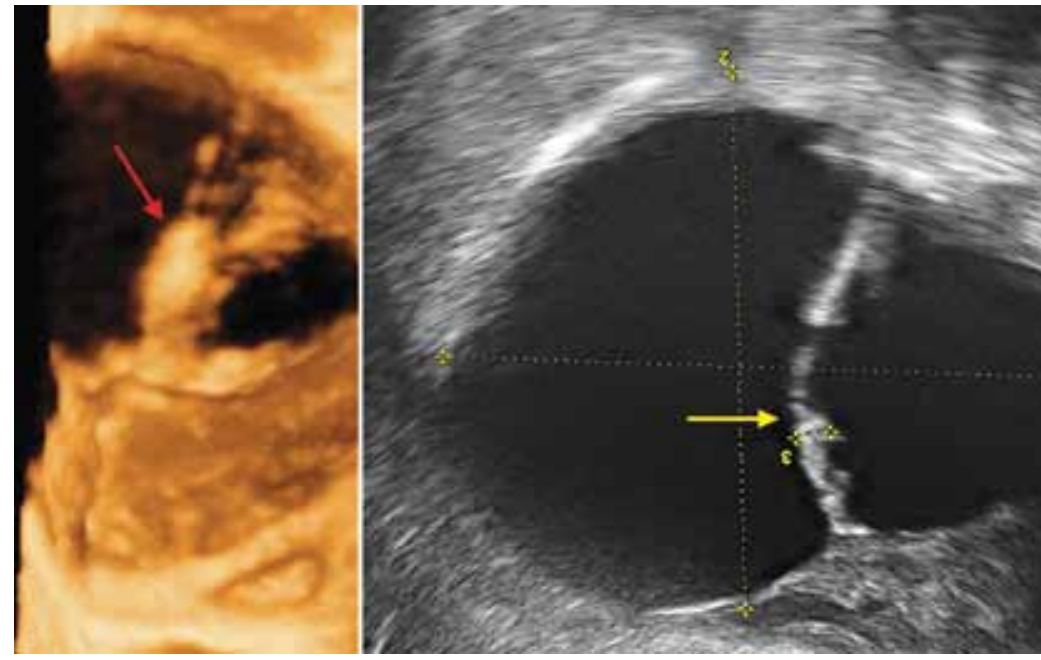

Fig. 28: Septated cyst. The septations are of different thickness (yellow arrow), and HDlive shows small papillae and exophytic grows (red arrow). In order to depict the image quality obtained with different ultrasound modes, please compare the two-dimensional US (to the right) with the 3D US (to the left) 


\section{REFERENCES}

1. Bonilla-Musoles F, El Ovaro (IV). Tumores malignos. In: Ecografia vaginal Doppler y tridimension. Panamericana Ed Med Madrid; 2001. p. 469-559. ISBN 84-7903-655-8.

2. Van Holsbeke C, Van Calster B, Valentin L, Testa AC, Ferrazzi E, Dimou I, Lu CH, Moerman P, Van Huffel S, Vergote I, et al. External validation of mathematical models to distinguish between benign and malignant adnexal tumors: a multicenter study by the international ovarian tumor analysis group. Clin Cancer Res 2007;13(15 Pt1):4440-4447.

3. Sayasneh A, Kaijser J, Preisler J, Smith A, Raslan F, Johnson S, Husicka R, Ferrrara L, Stalder C, Ghaem-Maghami S, et al. Accuracy of ultrasonography performed by examiners with varied training and experience in predicting specific pathology of adnexal masses. Ultrasound Obstet Gynecol 2015;45(4):605-612.

4. Jacobs I, Oram D, Fairbanks J, Turner J, Frost C, Grudzinskas J. A risk of malignancy index incorporating CA125, ultrasound and menopausal status for the accurate preoperative diagnosis of ovarian cancer. Br J Obstet Gynaecol 1990;97(10):922-929.

5. Alcazar JL, Merce L, Laparte C, Jurado M, Lopez-Garcia G. A new scoring system to differentiate benign from malignant adnexal masses. Am J Obstet Gynecol 2003;188(3):685-692.

6. Hata T, Hata K, Noguchi J, Kanenishi K, Shiota A Ultrasound for evaluation of adnexal malignancy: from $2 \mathrm{D}$ and $3 \mathrm{D}$ Ultrasound. J Obstet Gynecol Res 2011;37(10):1255-1268.

7. Timmerman D, Valentin L, Bourne TH, Collins WP, Verrelst $H$, Vergote I. Terms, definitions and measurements to describe the sonographic features of adnexal tumors: a consensus opinion from the International Ovarian Tumor Analysis (IOTA) group. Ultrasound Obstet Gynecol 2000;16(4):500-505.

8. Timmerman D, Testa AC, Bourne T, Ferrazzi E, Ameye L, Konstantinovic ML. International Ovarian Tumor Analysis Group. Logistic regression model to distinguish between the benign and malignant adnexal mass before surgery: a multicenter study by the International ovarian tumor analysis group. J Clin Oncol 2005;23(34):8794-8801.

9. Van Calster B, Van Hoorde K, Valentin L, Testa AC, Fischerova D, Van Holsbeke C, Savelli L, Franchi D, Epstein E, Kaijser J, et al. International ovarian tumor analysis group. Evaluating the risk of ovarian cancer before surgery using the ADNEX model to differentiate between benign, borderline, early and advanced stage invasive, and secondary metastatic tumours: prospective multicentre diagnostic study. Br Med J 2014;349: g 5920.

10. Bonilla-Musoles F, Cadete C, Raga F, Bonilla F Jr, Osborne NG, Caballero O. HDLive ultrasound images of ovarian dermoid cysts. Diagnostic accuracy. Clin Exp Obstet Gynecol 2015; 42(4):ref 2073/34.

11. Bonilla-Musoles F, Raga F, Osborne N, Bonilla F Jr, Castillo JC, Machado LE, Caballero O. Pictorical review: multimodality $3 \mathrm{D}$ volumetric ultrasound in obstetrics and gynecology with emphasis on HDlive technique. Ultrasound Q 2012;7(1):1-8.

12. Bonilla-Musoles F, Raga F, Bonilla F Jr, Castillo JC, Machado LE, Caballero O. Gynecological tumor images using HDlive. Donald School J Ultrasound Obstet Gynecol 2015; 9(2):1-10.

13. Hata T, Kanenishi K, Mashima M, Hanaoka U, Tanaka, H. HDlive rendering image of adnexal tumors: Preliminary report. J Med Ultrasonics 2014;41(2):181-186.
14. Raga F, Castillo JC, Bonilla F Jr, Caballero O, Bonilla-Musoles F. HDlive ultrasound images in assisted reproduction treatment. Reprod Biomed Online 2013;26(3):269-271.

15. Mihaela G. HDlive pictures of a serous ovarian borderline tumor. Ultrasound Obstet Gynecol 2013;41(5):598-599.

16. Ward GJ. The Radiance Lighting Simulation and rendering system. Proceedings of 94 SIGGRAPH Conference. Computer Graphics 1994;459-472.

17. Bonilla-Musoles F, Ballester MJ, Carrera JM. Doppler color transvaginal. Masson-Salvat Medicina 1992. Barcelona ISBN 84-458-0122-8.

18. Alcázar JL, Jurado M. Three-dimensional ultrasound for assessing women with gynecological cancer: a systematic review. Gynecol Oncol 2011;120(3):340-346.

19. Merz E. 25 years of 3D Ultrasound in prenatal diagnosis (1989-2014). Ultraschall Med 2015;36(1):3-8.

20. Bonilla-Musoles F, Raga F, Osborne NG. Three-dimensional ultrasound evaluation of ovarian masses Gynecol Oncol 1995;59(1):129-135.

21. Hata T, Yanagihara T, Hayashi K, Yamashiro C, Ohnishi $Y$, Akiyama M, Manabe A, Miyazaki K. Three-dimensional ultrasonographic evaluation of ovarian tumours: a preliminary study. Human Reprod 1999;14(3):858-861.

22. Alcázar JL, Galán MJ, García-Manero M, Guerriero S. Threedimensional ultrasound morphologic assessment in complex adnexal masses a preliminary experience. J Ultrasound Med 2003;22(3):249-254.

23. Alcázar JL, García-Manero M, Galván R. Three-dimensional sonographic morphologic assessment of adnexal masses: a reproducibility study. J Ultrasound Med 2007;26(8):1007-1011.

24. Laban M, Metawee H, Elyan A, Kamal M, Kamel M, Mansour G. Three-dimensional ultrasound and threedimensional power Doppler in the assessment of ovarian tumors. Int J Gynaecol Obstet 2007;99(3):201-205.

25. Jurkovic D. Three-dimensional ultrasound in gynecology: a critical evaluation. Ultrasound Obstet Gynecol 2002;19(1): 109-117.

26. Alcázar JL, Aubá M, Olartecoechea B. Three-dimensional ultrasound in gynecological clinical practice. Reports in Medical Imaging 2012;5(1):1-13.

27. Geomini PM, Kluivers KB, MoretE, Bremer GL, Kruitwagen RF, Mol BW. Evaluation of adnexal masses with three-dimensional ultrasonography. Obstet Gynecol 2006;108(5):1167-1175.

28. Vrachnis N, Sifakis S, Samoli E, Kappou D, Pavlakis K, Iliodromiti Z, Botsis D. Three-dimensional ultrasound and three-dimensional power Doppler improve the preoperative evaluation of complex benign ovarian lesions. Clin Exp Obstet Gynecol 2012;39(4):474-478.

29. Kurjak A, Kupesic S, Sparac V, Kosuta D. Three-dimensional ultrasonographic and power Doppler characterization of ovarian lesions. Ultrasound Obstet Gynecol 2000;16(4): 365-371.

30. Kurjak A, Kupesic S, Anic T, Kosuta D. Three-dimensional ultrasound and power Doppler improve the diagnosis of ovarian lesions. Gynecol Oncol 2000;76(1):28-32.

31. Kurjak A, Kupesić S. Three-dimensional ultrasound and power Doppler in assessment of uterine and ovarian angiogenesis: a prospective study. Croat Med J 1999;40(3): 413-420.

32. Crade M, Berman M, Chase D. Three-dimensional tissue block ultrasound in ovarian tumors. Ultrasound Obstet Gynecol 2005;26(6):683-686. 
33. Jokubkiene L, Sladkevicius P, Valentin L. Does threedimensional power Doppler ultrasound help in discrimination between benign and malignant ovarian masses? Ultrasound Obstet Gynecol 2007;29(2):215-225.

34. Pairleitner H, Steiner H, Hasenoehrl G, Staudach A. Threedimensional power Doppler sonography: imaging and quantifying blood flow and vascularization. Ultrasound Obstet Gynecol 1999;14(2):139-143.

35. Alcázar JL. Three-dimensional power Doppler derived vascular indices: what are we measuring and how are we doing it? Ultrasound Obstet Gynecol 2008;32(4):485-487.

36. Raine-Fenning NJ, Nordin NM, Ramnarine KV, Campbell BK, Clewes JS, Perkins A, Johnson IR. Evaluation of the effect of machine settings on quantitative three-dimensional power Doppler angiography: an in vitro flow phantom experiment. Ultrasound Obstet Gynecol 2008;32(4):551-559.

37. Schulten-Wijman MJ, Struijk PC, Brezinka C, De Jong N, Steegers EA. Evaluation of volume vascularization index and flow index: a phantom study. Ultrasound Obstet Gynecol 2008;32(4):560-564.

38. Martins WP, Raine-Fenning NJ, Ferriani RA, Nastri CO. Quantitative three-dimensional power Doppler angiography: a flow-free phantom experiment to evaluate the relationship between color gain, depth and signal artifact. Ultrasound Obstet Gynecol 2010;35(3):361-368.

39. Welsh A. The questionable value of VOCAL indices of perfusion. Ultrasound Obstet Gynecol 2010;36(1):126-127.

40. Martins WP. Three-dimensional power Doppler: validity and reliability. Ultrasound Obstet Gynecol 2010;36(4):530-533.

41. Utrilla-Layna J, Alcázar JL, Aubá M, Laparte C, Olartecoechea B, Errasti T, Juez L, Mínguez JA, Guerriero S, Jurado M. Performance of three-dimensional power Doppler angiography as a third-step assessment in differential diagnosis of adnexal masses. Ultrasound Obstet Gynecol 2015;45(5):613-615.

42. Van Holsbeke C, Yazbek J, Holland TK, Daemen A, De Moor B, Testa AC, Valentin L, Jurkovic D, Timmerman D. Real-time ultrasound vs evaluation of static images in the preoperative assessment of adnexal masses. Ultrasound Obstet Gynecol 2008;32(6):828-831.

43. Alcázar JL, Díaz L, Flórez P, Guerriero S, Jurado M. Intensive training program for ultrasound diagnosis of adnexal masses: protocol and preliminary results. Ultrasound Obstet Gynecol 2013;42(2):218-223.

44. Sajapala S, AboEllail MAM, Tanaka T, Nitta E, Kanenishi K, Hata T. New 3D power Doppler (HDliveFlow) with HDlive silhouette mode for diagnosis of malignant ovarian tumor. Ultrasound Obstet Gynecol 2015.

45. Pooh RK. Brand new technology of HDlive Silhouette and HDive Flow images. In: Pooh RK, Kurjak A: Donald School Atlas of Ultrasound in Obstetrics and Gynecology. Chapter 1. New Dehli: The Health Science Publishers. Jaypee Brothers Medical Publishers (P) Ltd.; 2015. p. 1-38.

46. AboEllail MAM, Kanenishi K, Mori N, Kurobe A, Hata T. HDlive image of circumvallate placenta. Ultrasound Obstet Gynecol 2015;46(4):513-514.

47. AboEllail MAM, Kanenishi K, Tenkumo C, Mori N, Katayama T, Koyano K, Kusaka T, Hata T. 4D power Doppler with HDlive silhouette mode in antenatal diagnosis of right aortic arch with an aberrant left subclavian artery. J Ultrasound Med 2015 (in press).

48. AboEllail MAM, Tanaka H, Mori N, Hanaoka U, Hata T. HDlive silhouette mode in antenatal diagnosis of jejunal atresia. Ultrasound Obstet Gynecol 2015 Sep 4. Doi: 10.1002/ uog.15737 